\title{
An interdisciplinary review of energy storage for communities: challenges and perspectives
}

David Parra ${ }^{a 1}{ }_{\text {. Maciej Swierczynskib }}$, Daniel I. Stroe ${ }^{\mathrm{b}}$, Stuart. A. Norman ${ }^{\mathrm{c}}$, Andreas Abdon ${ }^{\mathrm{d}}$, Jörg Worlitschek ${ }^{d}$, Travis O'Dohertye ${ }^{e}$ Lucelia Rodrigues ${ }^{e}$, Mark Gillotte ${ }^{e}$ Xiaojin Zhang ${ }^{f}$, Christian Bauerf, Martin K. Patela.

a Energy Efficiency Group, Institute for Environmental Sciences and Forel Institute, University of Geneva, Boulevard Carl-Vogt 66, 1205 Genève, Switzerland

b Department of Energy Technology, Aalborg University, Pontoppidanstræde 111, Aalborg 9220, Denmark

c E.ON UK plc. Ratcliffe on Soar, Nottingham NG11 0EE, UK

d Lucerne University of Applied Sciences \& Arts. Technikumstrasse 21, 6048, Horw, Switzerland

e Department of Architecture and Built Environment, Faculty of Engineering, University of Nottingham, University Park, NG72RD UK

${ }^{\mathfrak{f}}$ Technology Assessment Group, Paul Scherrer Institut, Villigen PSI, Switzerland

\section{Abstract}

Given the increasing penetration of renewable energy technologies as distributed generation embedded in the consumption centres, there is growing interest in energy storage systems located very close to consumers. These systems allow to increase the amount of renewable energy generation consumed locally, they provide opportunities for demand-side management and help to decarbonise the electricity, heating and transport sectors.

In this paper, the authors present an interdisciplinary review of community energy storage (CES) with a focus on its potential role and challenges as a key element within the wider energy system. The discussion includes: the whole spectrum of applications and technologies with a strong emphasis on end user applications; techno-economic, environmental and social assessments of CES; and an outlook on CES from the customer, utility company and policy-maker perspectives. Currently, in general only traditional thermal storage with water tanks is economically viable. However, CES is expected to offer new opportunities for the energy transition since the community scale introduces several advantages for electrochemical technologies such as batteries. Technical and economic benefits over energy storage in single dwellings are driven by enhanced performance due to less spiky community demand profile and economies of scale respectively. In addition, CES brings new opportunities for citizen participation within communities and helps to increase awareness of energy consumption and environmental impacts.

Keywords: energy storage; community; renewable energy technologies; interdisciplinary review

\section{Terminology}

\section{- CAPEX: capital expenditure}

\footnotetext{
${ }^{1}$ e-mail: david.parra@unige.ch

${ }^{2}$ Moved to Eastern and Midland Regional Assembly. Current e-mail address: TODoherty@emra.ie
} 
- CES: community energy storage

- CHP: combined heat and power

- DHW: domestic hot water

- DSO: distribution system operator

- EV: electric vehicle

- ES: energy storage

- EV: electric vehicle

- FiT: feed-in tariff

- FC: fuel cell

- GHG: greenhouse gas

- HP: heat pump

- IRR: internal rate of return

- LCA: life cycle assessment

- Li-ion: lithium-ion

- $\mathrm{PbA}$ : lead-acid

- PCM: phase change material

- PEM: polymer electrolyte membrane

- PEMFC: polymer electrolyte membrane fuel cell

- PV: photovoltaics

- RE: renewable energy

- RTP: real-time-pricing

- SOFC: solid oxide fuel cell

- ToU: time-of-use

\section{Introduction}

The pressure to cut greenhouse gas (GHG) emissions and to save fossil fuels has directed attention to solutions that can contribute to meeting society's energy needs while minimising associated GHG emissions. The most widely endorsed solutions are renewable energy (RE) technologies and energy efficiency, while nuclear energy and carbon capture and storage are generally viewed more critically. RE has been the fastest growing technology and since 2011 accounted for more than half of all capacity built in the power sector. In $2013,22 \%$ of the global electricity supply was provided by RE sources (a $51.3 \%$ increase from 2004) [1]. While the main contributor to that share, hydro $(76.4 \%$ of the global renewable electricity generation), is a dispatchable supply source (run-off river installations to a lesser extent), the faster growing technologies, namely wind turbines and solar photovoltaics (PV) energy are stochastic since their generation profiles are intrinsically linked with the weather conditions [2]. Another important characteristic of solar PV and wind systems is their modularity. Solar and wind generators have been extensively installed within distributed power generation systems, i.e. close to the demand centres. This is particularly the case for PV since $48 \%$ and $34 \%$, respectively, of the total installed capacity correspond to installations with a nominal power lower than $50 \mathrm{~kW}_{\mathrm{p}}$ in the UK and $40 \mathrm{~kW}_{\mathrm{p}}$ in Germany, respectively [3, 4]. In contrast, the power capacity of both wind generators and wind farms are increasing due to economies of scale.

From the demand side perspective, key challenges arise from the decarbonisation of heating demand and the transport sector. In this context, coupling of low GHG electricity generation with heat pumps (HPs) and electric vehicles (EVs) are currently being proposed in several countries. For example, HPs accounted for $9 \%$ and $12 \%$ of the space heating supply in Germany and Switzerland in 2012 respectively [5], but this share is $30 \%$ for newly built houses in Germany. By 2030 , between $17 \%$ and $29 \%$ of space heating demand in Germany 
is expected to be provided by HPs according to market forecasts [6]. In view of further R\&D needs and regulatory gaps [7] as well as prevailing market forces and consumer preferences, these technologies are expected to become dominant only within the 20302050 timeframe.

Against this background, technologies providing additional flexibility to energy systems should be implemented, however without relying on fossil fuels. Energy storage (ES) is attracting increasing attention as it improves the dispatchability of RE technologies while handling different energy carriers such as electricity, heat and gases and creates a more integrated energy system. Within the ES domain, community energy storage (CES) is emerging as a modular concept to be implemented close to energy consumption centres in connection with RE plants owned by end users. CES could support further penetration of distributed RE technologies through: i) allowing end users to shift surplus generation to meet their demand load later; ii) maintaining grid stability (i.e., by supplying matching capability, compensating peak demand and offering solutions for related balancing issues); iii) internalising system benefits into economic revenues when taking part in different markets e.g., electricity wholesale and frequency markets; iv) and catalysing grassroots initiatives with the participation of community members that facilitate the socio-economic development of the district/community.

Several review studies on ES have been published given its relevance for future energy systems. Some of the first reviews, for example by lbrahim et al. [8], Chen et al. [9] and Huggins [10], discussed the ES concept and mission including the whole spectrum of ES applications, technologies and related key technical characteristics such as capacity, efficiency and durability. Other authors reviewed a part of the full spectrum of ES applications and related technologies, e.g. the review of electricity storage applications by Brunet [11]; a review of ES technologies for wind power applications by Díaz-González et al. [12]; and the review of phase change materials (PCMs) for building applications by Cabeza et al. [13]. Given the continuous attention to ES, recent reviews have become more specific, focussing on the recent development of a particular technology, application, scale and/or country. Some examples are the evaluations of Stan et al. on lithium-ion (Li-ion) batteries for power and automotive applications [14]; Niaz et al. on hydrogen storage [15]; Lyons et al. on demonstrations projects in UK distribution grids [16]; and a comparative analysis of the life cycle cost of different ES technologies by Zakeri et al. [17].

Considering the increased self-generation of energy and the modularity of several ES technologies, communities have been recently suggested as a key scale for energy systems $[18,19]$ and ES in particular, allowing to make use of significant technical advantages [2022]; to exploit economic benefits [21, 23] and to engage local communities and promote social development linked with local RE supply [24-27]. Some reviews on CES have already been published. For example, Zhu et al. discussed distributed ES using battery technology for residential community applications [28]. B.P Roberts analysed its role for the development of smart grids [29] while Asgeirsson provided a brief update on the status of CES projects funded by Department of Energy (USA) [30]. All these previous studies and reviews on CES (and distributed ES in general) share similar characteristics. Firstly, the main focus was on technologies and applications supporting optimum electricity grid performance. Secondly, electricity and heat storage were discussed independently even though technologies such as HPs and combined heat and power (CHP) units connect both demands. Finally, no particular interest was paid to the role of end users (customers who consume and potentially generate energy, electricity and heat at home) although they are an important driver of the energy transition by purchasing and using RE and/or other lower carbon technologies. Therefore, there is a need for a more comprehensive review on CES 
that considers the multiple benefits of CES holistically: a) including CES applications depending on the involved stakeholder, i.e. end user, utility company and/or distribution system operator (DSO); b) considering different temporal ES scales for both electricity and heat; c) analysing the impacts of CES across the three pillars of sustainability (namely economy, environment and society); and d) discussing the role of different stakeholders such as end users, utility companies and policy-makers.

\section{Scope of this review}

CES has been suggested as an intermediate solution between single-home ES systems and grid-scale ES systems, for balancing local intermittent RE generation and dynamic demand loads including HPs and EVs in residential areas [29]. The scale of single home, community and grid scale ES is schematically represented in Fig. 1Fig. 1 and compared in Table 1 Table

Table 1: Comparison of the features of ES implementation at different scales, adapted from [22].

\begin{tabular}{|c|c|c|c|c|}
\hline & Bulk & Grid-scale & Community & Single home \\
\hline $\begin{array}{l}\text { Most beneficial } \\
\text { applications }\end{array}$ & $\begin{array}{c}\text { For } \\
\text { generators } \\
\text { and the } \\
\text { network }\end{array}$ & $\begin{array}{l}\text { For the network } \\
\text { (regional } \\
\text { electricity and/or } \\
\text { heat network) }\end{array}$ & $\begin{array}{l}\text { For the end } \\
\text { users and the } \\
\text { network }\end{array}$ & $\begin{array}{l}\text { For the end } \\
\text { user }\end{array}$ \\
\hline $\begin{array}{l}\text { Scale (ES } \\
\text { capacity) }\end{array}$ & MWh-GWh & MWh & $\begin{array}{c}\text { Tens or } \\
\text { hundreds of kWh }\end{array}$ & Up to $20 \mathrm{kWh}$ \\
\hline Location & $\begin{array}{l}\text { Connected } \\
\text { to electricity } \\
\text { transmission } \\
\text { networks }\end{array}$ & $\begin{array}{l}\text { Connected to } \\
\text { electricity or heat } \\
\text { transmission } \\
\text { networks }\end{array}$ & $\begin{array}{l}\text { Connected to } \\
\text { local distribution } \\
\text { networks }\end{array}$ & $\begin{array}{l}\text { "Behind the } \\
\text { meter" in single } \\
\text { properties }\end{array}$ \\
\hline
\end{tabular}

Table 1Table 1 can serve as starting point for a comparative analysis of CES. Some of the services potentially provided by CES systems have been previously investigated in single homes or for distribution networks (typically next to the transformer between the transmission and distribution grids). Therefore, methodological aspects, results and/or demonstrations from ES utilised in single homes, districts or distribution networks are also included in this review when relevant but differences with the CES scale are highlighted when necessary. The residential sector is the centre of attention of this study but commercial buildings can be also integrated within communities. In this case, the CES capacity requirements may be different given the different demand patterns of commercial buildings. As remote communities isolated from the main electricity network have already been identified in the literature as one of the most important economic and sustainable applications of CES systems [31], they will not be part of the scope of this work. However, some of the technical conclusions elaborated in this study, mainly those related to ES technologies, mini-grids and end user applications, also apply for off-grid applications and autonomous communities. This review is not limited geographically but most examples are taken from countries with fast diffusion of RE and other low carbon technologies and in the case of thermal storage, with temperate climate. Results are primarily taken from experience made with existing systems although some ex-ante modelling is considered for future developments. 


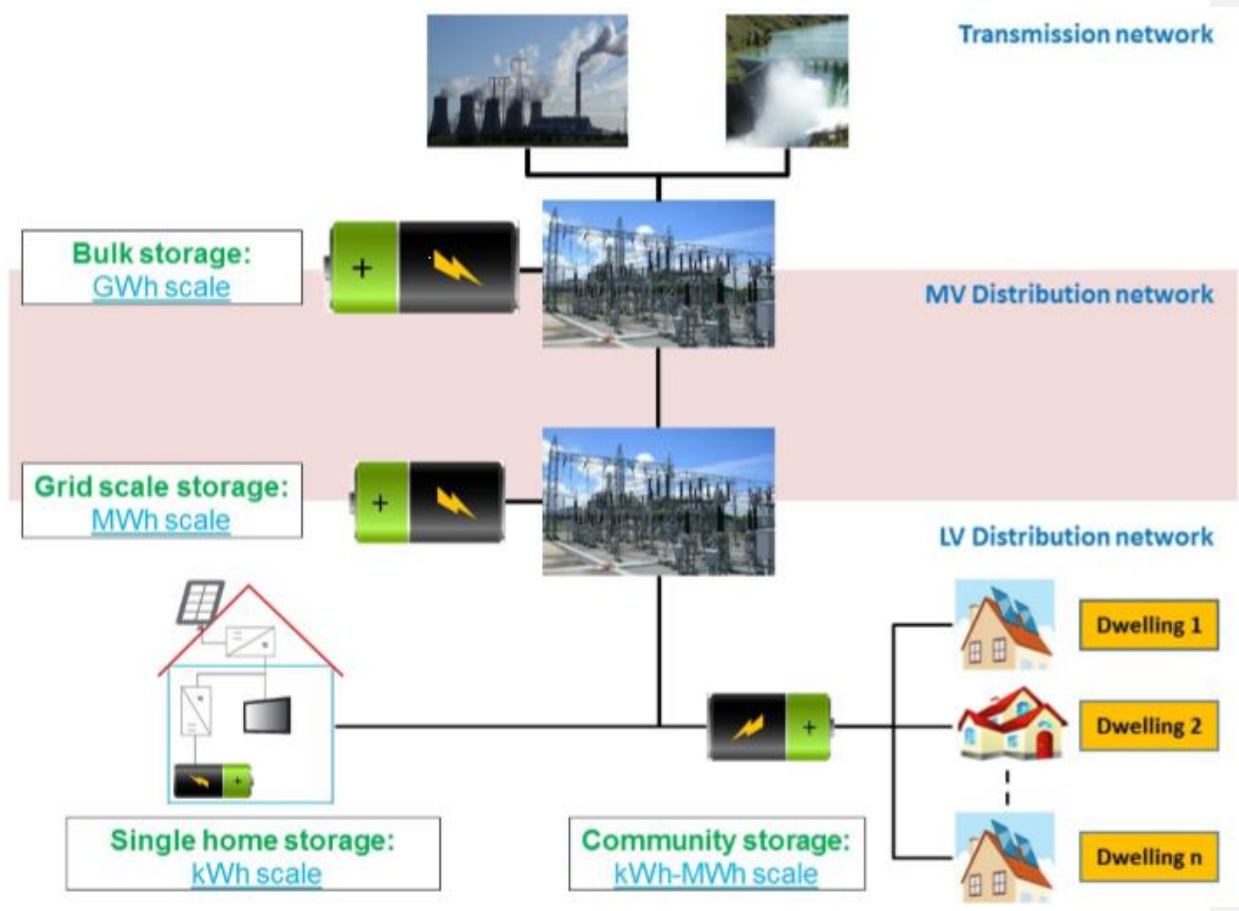

Fig. 1: Schematic representation of the scale of CES studied in this paper in comparison with single home and grid-scale ES.

From a technology perspective, the solutions presented in this paper are those which are the most suitable for community applications without addressing mobility applications. Thus, technologies such as pumped-hydro and compressed-air ES are not considered in this review because they are not modular for the community scale (typically they are used for the MW/GW scale) and they have special requirements in terms of geographical locations [10]. Furthermore, 'power' technologies such as flywheels and supercapacitors are only considered as part of hybrid systems due to their limited ES capability [9, 32-34] which are not well-matched to the demands required by CES applications.

\section{End user applications}

CES applications which have a direct impact on the energy bills of end users are discussed in this section. For example, CES could be utilised for increasing the amount of locallyconsumed energy generated from RE plants; or shifting part of the electricity import to offpeak periods; and/or reducing the capacity rating of a heat supply system. In this study, these applications are referred to as "end user applications" [21, 35]. The first variant of this application, self-consumption, is described using solar PV as an example since it has been the fastest-growing RE technology worldwide over the last decade (cumulative installed capacity has grown at an average rate of approximately $50 \%$ per year) and is very suitable for the built environment [36]. However, similar self-consumption strategies are being utilised for other RE generators implemented in the built environment, namely solar thermal collectors and wind generators. 


\subsection{PV strategies beyond self-consumption}
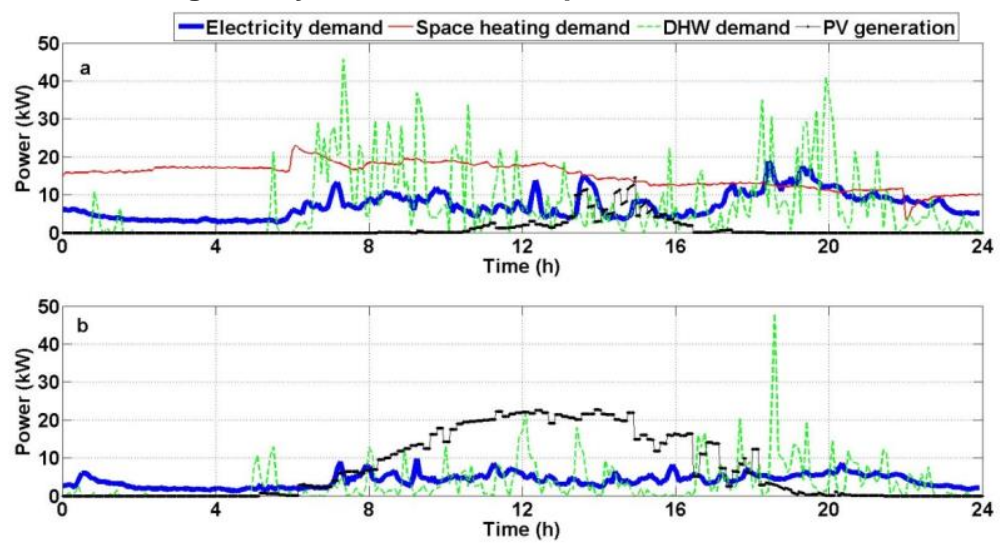

Fig. 2: Electricity, domestic hot water (DHW) and space heating monitored demands and as well as simulated PV generation from a $25 \mathrm{~kW}$ PV array in a 12-dwelling low carbon community (Minergie standard) located in Geneva: (a) 15 January; and (b) 15 July [37]

Volatile energy production by PV systems causes mismatch between peak-demands periods of power production and consumption on a daily basis as shown in Fig. 2 Fig. 2 for a low community in Geneva. This creates technical (voltage and frequency variation) and economic challenges (expensive dispatch due to the use of more costly generation sources) in the electricity system as discussed in Section 6. Fig. 2Fig. 2 also illustrates the seasonal mismatch since more PV energy is generated during summer days when demand is lower. At the moment, the most common usage for PV-coupled CES systems is maximisation of self-consumption. It aims to shift any surplus PV generation to meet local demand later. PV self-consumption has been intensively investigated in single homes given the important penetration of PV technology at this scale $[38,39]$. However, by means of model-based assessments, Parra et al. determined the levelised cost of batteries for communities ranging from a single home up to 100 homes and concluded that the community approach reduced the levelised cost by $37 \%$ as compared to single-home residential battery systems in a projected 2020 scenario in the UK (assumed electricity price and discount rate of 0.24 US $\$ 3 / \mathrm{kWh}$ and $10 \%$ respectively) [22]. This improvement was possible due to the benefits of aggregation of demands across the various homes (see Fig. 3Fig. 3 ) on the battery and the reduction of the capital expenditure (CAPEX) due to economies of scale [22].

\footnotetext{
${ }^{3} 1.4$ is the assumed conversion rate between British pound and US dollar
} 


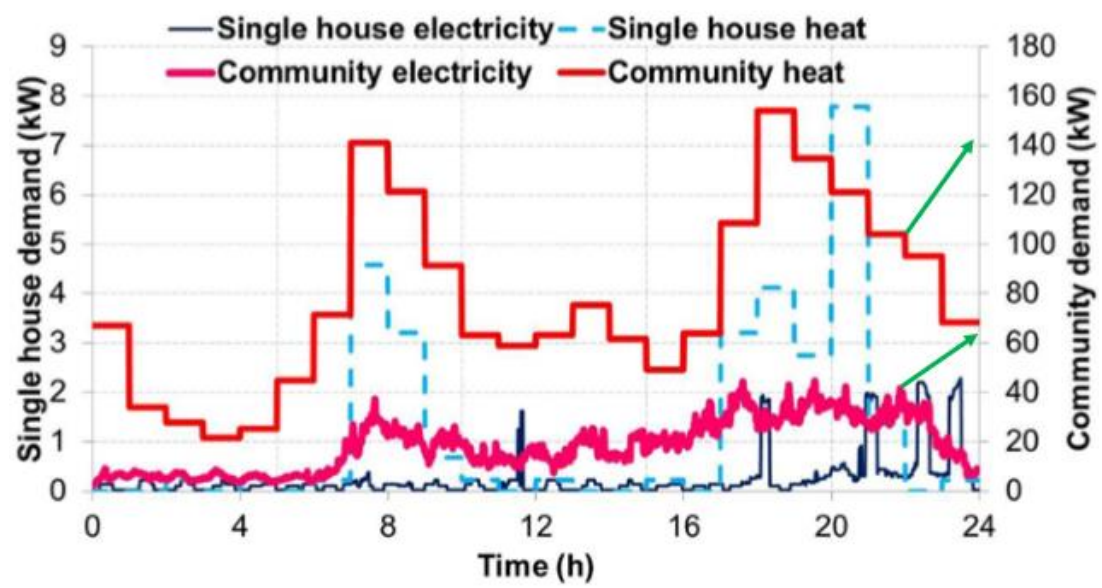

Fig. 3: Electricity and heat demand (both space heating and DHW) of a single home and 50 homes monitored in a community located in the UK (Milton Keynes) with a temporal resolution of 1 minute and 1 hour respectively.

The economic driver for performing PV self-consumption is the higher price of the electricity imported to a dwelling (i.e. purchased), $P_{\mathrm{i}}(U S \$ / k W h)$, in comparison to the value assigned to the exported PV electricity (i.e. sold), $P_{\text {ex }}$ (US $\left.\$ / k W h\right)$. $P_{e x}$ corresponds to the electricity price in the wholesale market or alternatively to a feedin tariff (FiT) support scheme. The price of imported electricity $\mathrm{P}_{\mathrm{i}}$ is three to four times larger than $P_{e x}$ [40]. Therefore, $P V$ self-consumption is more attractive in countries which limited (or removed) the FiT related to the electricity export, a decision which is increasingly being taken because of the high societal costs of FiTs, achievement of grid parity (Germany) [41] and/or support policy change after a certain level of installed capacity has been reached as well as a more market-oriented strategy (e.g., UK and Switzerland) [42] [43]. Equation (2), derived from Equation (1), is used to determine the revenue generated by performing $\mathrm{PV}$ self-consumption in which $\mathrm{E}_{\text {char }}$ $(\mathrm{kWh})$ and $\mathrm{E}_{\text {dis }}(\mathrm{kWh})$ refer to the CES charge and discharge [22]. The round trip efficiency of the CES system, $\eta$, is the ratio of the battery discharge to the charge including the efficiency of the bidirectional inverter.

$$
\begin{aligned}
& \operatorname{Rev}_{P V s c}=E_{\text {dis }} \times P_{i}-E_{\text {char }} \times P_{e x} \\
& \operatorname{Rev}_{P V s c}=E_{\text {char }} \times P_{i} \times\left(\eta-\frac{P_{e x}}{P_{i}}\right)
\end{aligned}
$$

In addition to the available surplus PV energy, the most important parameters for maximising the value created by PV self-consumption are the electricity retail price $\left(\mathrm{P}_{\mathrm{i}}\right)$ and the round trip efficiency of the CES system. The available surplus energy depends on the local irradiance and the rating of the PV installation (relative to the local community demand), while the economic benefits are proportional to the PV penetration of the community (defined as the percentage of homes with a PV installation), with percentages higher than $75 \%$ needed for minimising the levelised cost and maximising the profitability [22]. Germany ( $P_{i}$ equal to 0.33 US $\$ 4 / \mathrm{kWh})$, Denmark (0.36 US $\$ / \mathrm{kWh})$ and Australia $\left(0.26^{5} \mathrm{US} \$ / \mathrm{kWh}\right)$ are examples of

${ }^{4} 1.15$ is the assumed conversion rate between EURO and US dollar

${ }^{5} 0.77$ is the assumed conversion rate between Australian dollar and US dollar 
countries where PV self-consumption is attractive at the moment from a retail electricity price perspective. The round trip efficiency strongly depends on the ES technology utilised for CES. Li-ion batteries, which are discussed in Section 7.2, with a round trip efficiency ranging from $80-90 \%$ [44] are the most suitable technology for the required daily charge/discharge cycles. According to Fig. 2Fig. 2, the battery could potentially charge up to 6 hours on a daily basis but this is typically reduced to 2 hours due to optimum techno-economic sizing (in order to maximize the number of days the battery is fully charged) [22]. However, other technologies including PbA batteries [22], hydrogen, redox batteries [45] and hot water tanks [46] have also been utilised and analysed both in modelling and experimental work. Recent research has also addressed how PV-coupled CES could be utilised in order to introduce further benefits to the electrical system beyond self-consumption. The main strategies for PV-coupled CES systems are outlined in Table 2Table 2.

Table 2: Different control strategies which could be implemented with a CES system connected to a PV system.

\begin{tabular}{|cc|}
\hline \multicolumn{1}{|c|}{ PV strategies } & References \\
\hline Maximisation of self-consumption & {$[22,47,48]$} \\
\hline Reduction of peak export & {$[49,50]$} \\
\hline Reduction of peak import & {$[47,49]$} \\
\hline Advanced Battery management & {$[51,52]$} \\
\hline PV electricity constant supply & {$[53,54]$} \\
\hline Seasonal storage & {$[55,56]$} \\
\hline Reduction of PV output variation/control of ramp-rates & {$[47,57]$} \\
\hline Fully programmable PV production profile & {$[58,59]$} \\
\hline
\end{tabular}

\subsection{Demand strategies beyond load shifting}

Given its location near to end-users, CES systems can also be operated to perform costoptimisation of (retail) electricity tariffs which vary throughout the day, i.e. time-varying tariffs. These tariffs are offered by utility companies in order to translate the wholesale market price (i.e. system fuel cost) by hour to end users and/or promote the smoothing of the daily demand peak by using more cost-effective base load generation. By analogy with PV selfconsumption, the revenue of a CES system performing demand load shifting can be determined using Equation (4) derived from Equation (3), in which $P_{i-p}, P_{i-o p}$ and period refer to the peak electricity import price, off-peak electricity import price and the number of periods of the tariff.

$$
\begin{aligned}
& \operatorname{Rev}_{D L S}=\sum_{\substack{p=1 \\
\text { period }}}^{\text {period }} E_{\text {dis }} \times P_{i-P}-E_{\text {char }} \times P_{i-o p} \\
& R e v_{D L S}=\sum_{p=1} E_{\text {char }} \times P_{i-p} \times\left(\eta-\frac{P_{i-o p}}{P_{i-p}}\right)
\end{aligned}
$$

In the context of CES systems, time-of-use (ToU) tariffs (defined as those in which the number of periods and related price value are constant throughout the day and known by customers in advance) have been the most studied options. Zheng et al. determined the profit for 15 different ES technologies performing demand load shifting in an "average" single house in USA. Profits varied from $1 \%$ to $48 \%$ of the annual electricity costs depending on the technology and type of ToU tariff. Short-term ES became more competitive when the ToU tariff included a capacity component but cost was still higher than profit for all ES technologies [60]. Alternatively, tariffs in which the number of periods per day and/or the 
price value vary depending on electricity prices in wholesale markets, i.e. real-time pricing (RTP) tariffs, have also been studied. Using a mixed-integer linear programming (MILP) framework, Erdinc et al. quantified the required battery capacity depending on different dynamic response based load patterns [61]. The coupling of CES and demand response programs was suggested in order to anticipate the optimum ES capacity. Parra et al. optimised CES systems using PbA and Li-ion technology for both ToU and RTP tariffs [62] for a projected scenario in 2020. The discharge value for demand load shifting was lower than for PV energy time-shift since the price of the exported electricity in Equation (2) is lower than the off-peak price in Equation (4). $\mathrm{PbA}$ batteries with a storage medium cost equal to $210 \mathrm{US} \$ / \mathrm{kWh}$ were more economically viable than Li-ion batteries (storage medium cost of $430 \mathrm{US} \$ / \mathrm{kWh}$ ) for demand load-shifting (without rewarding demand peak shaving) because this application requires conservative ratios of power rating to energy capacity. Electricity and heat demand load shifting with hydrogen storage have also been experimentally demonstrated for a low carbon community in Nottingham (UK) [63]. The energy rating is decoupled from the power rating and this allowed the electrolyser to run at full load when the electricity price was very low and provided energy for days afterwards, i.e. operating as mid and long term ES (as compared to battery storage).

Beyond shifting energy demand (kWh) from peak to off-peak periods based on energy prices, CES systems have also the potential of minimising the electricity demand (grid import) peaks, so called demand peak-shaving. This application becomes more relevant for the residential sector when heating, cooling and/or EV demand loads are supplied with electricity-driven technologies [64]. Although this application is very relevant for DSOs in charge of distributing electricity to end users (and accordingly liable for the cost of upgrading the distribution infrastructure to meet any increase in peak demand), end users with a CES system can only economically benefit from it when the tariff has a capacity component [65]. A detailed analysis of end-user reactions and the related grid upgrade costs, i.e. residential price-reflectivity on capacity tariffs, was performed by Jargstorf et al. using capacity tariffs [66]. A case study led to the conclusion that an import capacity tariff does not guarantee a final cost reduction for the DSO but this changed when a capacity component on the PV injection was also added.

The spectrum of ES technologies available for peak shaving is wide, e.g. battery for communities with EVs and HPs [64]; PCM for space heating and freezer applications [67]; cold thermal storage for cities in semiarid areas [68]; and cold thermal storage for commercial buildings [69]. The main drivers for the use of CES systems for managing electricity demand in communities together with the different types of tariffs which could be implemented to incentivise end users' participation are schematically presented in Fig. 4Fig. Regardless of the type of tariff, demand forecast techniques are required to maximise the techno-economic benefits, i.e. it is essential to anticipate how much CES capacity is required and when it should be available for shifting the demand to off-peak. 


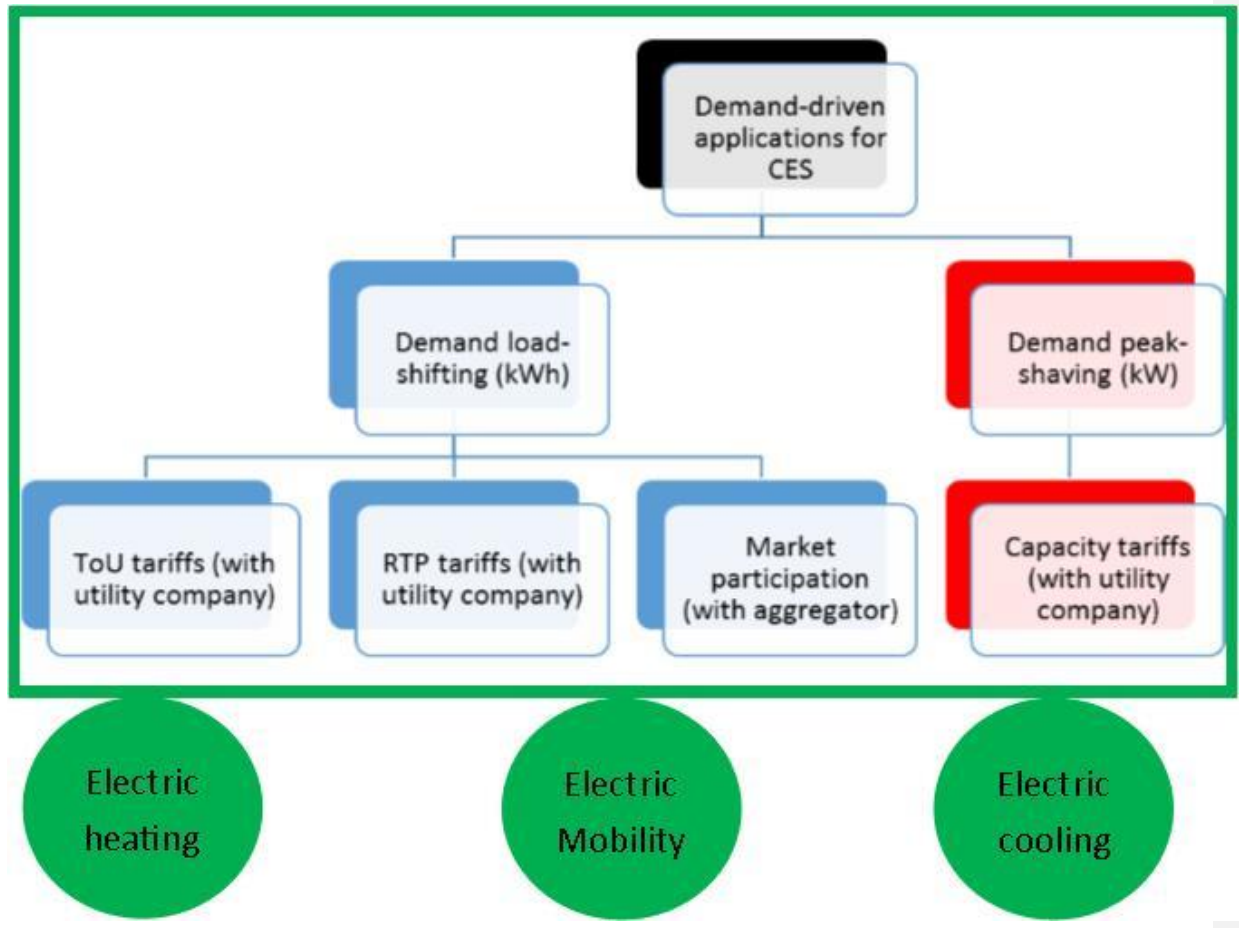

Fig. 4: Schemat representation of the different drivers for the management of community demands by CES systems

\subsection{Heat supply and heat demand management}

From a demand perspective, both space heating and DHW demands require moderate temperatures around $30^{\circ} \mathrm{C}$ and $55^{\circ} \mathrm{C}$ respectively, but the former is still $3-5$ times larger in new households in regions with temperate climate. Likewise, DHW demand remains fairly constant over the year, but the space heating demand of a building typically has a significant variation according to changing ambient conditions in different seasons. As shown in Fig. for residential building located in Strasbourg (several different building envelopes being considered: 15,45 and $100 \mathrm{kWh} / \mathrm{m} 2$ p.a.), the heating demand is zero in summer and reaches its maximum in winter whereas the available solar energy shows the opposite characteristics with a winter period peak supply of only one third of the summer peak supply. 

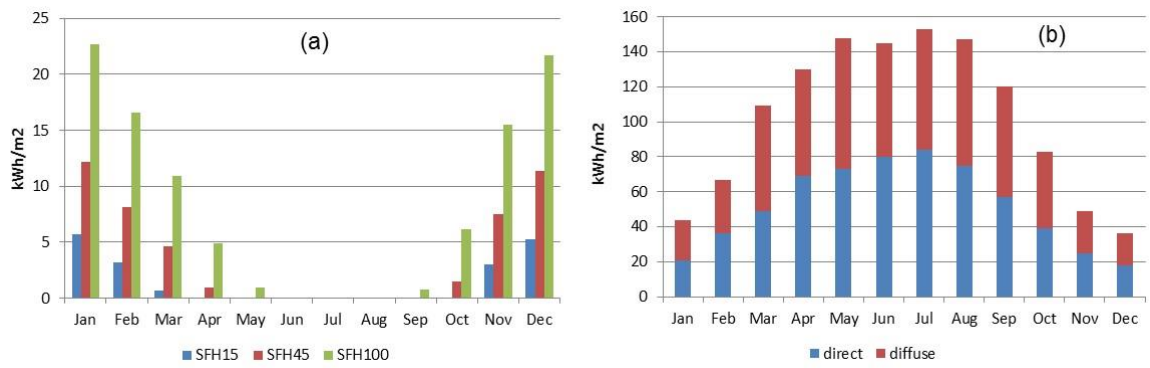

Fig. 5: (a) Heating demand for a single family home in Strasbourg of different building envelope designs referred to as SHF 15, SHF 45 and SHF 100 (i.e. 15, 45 and $100 \mathrm{kWh} / \mathrm{m} 2$ p.a.); (b) Available solar thermal energy. With permission from [70].

The mismatch between heat demand and supply represents an opportunity for CES since several benefits can be generated by decoupling of the energy demand and supply. In the evaluation of Goh et al. [71], a seasonal storage solution in the form of a helical borehole CES is used for levelling the winter peak demand for several large buildings. In combination with a HP, this solution results in a system which only requires $1 \mathrm{kWh}$ of electricity to generate $10 \mathrm{kWh}$ of heat on an annual basis (i.e. annual coefficient of performance equal to 10). During the colder seasons short term CES may be needed due to day and night variations in ambient temperature and the lack of solar energy supply during night. For this purpose water based thermal CES systems and PCMs may be applicable and it is also possible to use the building itself as a passive ES system [72]. PCMs integrated into the building envelope can provide energy savings and reductions in peak demand in the order of $15-20 \%[73]$

The use of thermal ES for demand peak shaving is also commonly found in building heating applications [74] and cooling applications [75] as a means of cost reduction. With the installation of cold water or ice storage, the investment cost of the chiller and cooling tower can be lowered and (in most cases) more importantly the electricity connection fee is significantly reduced. As discussed in the previous section, the exploitation of tariffs is also a factor that can incentivise thermal based CES as a supplement to chillers as well as HPs [69]. Although thermal based CES creates most value in terms of primary energy savings and GHG emission reductions in direct combination with RE sources, its integration with other efficient technologies such as CHPs and HPs is being proposed. For example, local electricity generation with CHP units may benefit from high electricity prices during peak electricity demand which often does not coincide with the peak heating demand [76]. Likewise, electricity demand side management with thermal storage together with HPs, chillers or electrical boilers is also being used for reducing peak loads in the electricity grid [77] and may also displace fossil-based peak load units for electricity generation [78].

\section{Distribution network applications and electricity markets}

The reduction of barriers for ES technologies to participate in the ancillary services markets has given a boost to ES penetration in the grid and the penetration is expected to continue increasing [79]. This is especially visible in California, where the Federal Regulatory Commission has removed barriers for ES systems to participate in ancillary service markets as well as introduced structural changes, which are favourable for fast reacting ES systems with high accuracy of the power output control increasing $[79,80]$. There is a high number of 
potential CES applications in the electricity markets and in the distribution network, as schematically represented in Fig. 6 Fig. 6 , which were so far mostly provided by nonenvironmentally friendly generation units. In the following part, the overview of the most important ancillary services for CES systems is presented. Given the fact that these applications have been more analysed and detailed in the previous literature [ref1, ref2], only a brief discussion of the full spectrum of electricity markets and distribution networks applications is presented here.
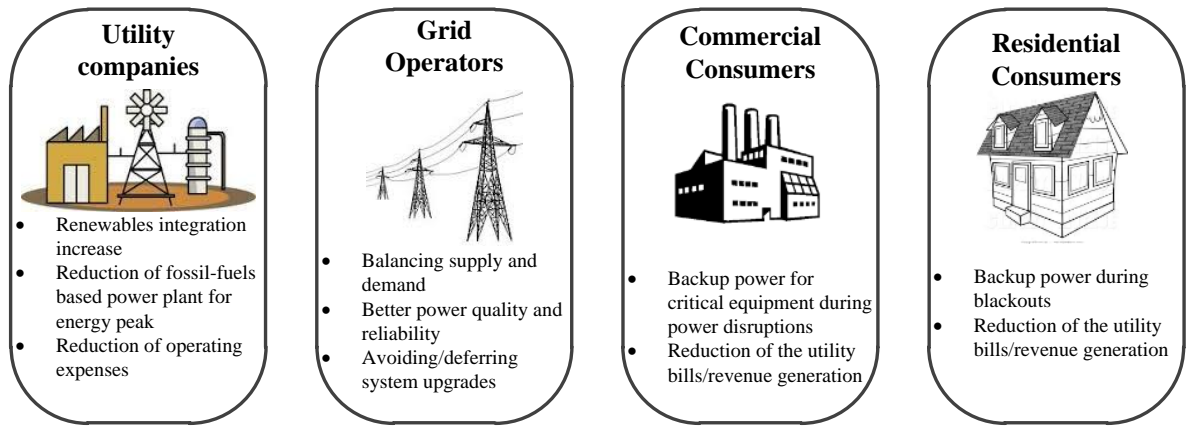

Fig. 6: Benefits from ES technologies across different segments of the power system [81-83].

\subsection{Arbitrage in the wholesale electricity market}

This application is conceptually equivalent to demand load-shifting and the only difference relies on the participation in the electricity wholesale market. Based on the market prices, CES systems are charged with low price electricity (typically during periods with low demands or large RE generation) and selling electricity later the price is high (typically at peak demand periods) [81, 84]. The market participation is possible under the role of "an aggregator" for communities enabling the interaction between the upper-level market and end users [85] [86]. For this purpose, Arghandeh et al. presented a real-time control strategy to maximize the revenue of CES systems operating in competitive markets [23]. The focus was oin the impact of key practical limiting factors including power feeder loses (with little impact), accuracy versus computational time, price and demand load forecast (with a high impact).

\subsection{Frequency regulation}

It is one of the most popular and most profitable application of ES. For this service, CES systems can contribute- suppressing the fluctuations of the frequency in a grid, which has a source of imbalance between generation and load [87]. If a generator or a whole grid is overloaded the generator slows down and the frequency drops. If the present load is less than the present production, the generator speeds up, and the frequency increases [88]. Especially in grids with high wind penetration levels, sudden reduction of the wind resource can significantly contribute to frequency drop [87]. Thus, a CES system should deliver power (discharging) into the grid in case of electricity grid under frequency or consumes power from the grid (chargescharging) for electricity grid over frequency [87]. Frequency regulation services, depending on the required reaction time and time-scale is often divided into: primary, secondary and tertiary [81]. CES systems are suitable for primary frequency regulation service due to limited discharge time and fast responses.

\subsection{Distribution network capital deferral}

Commenté [MAS1]: Koirala, Binod Prasad, et al. "Energetic communities for community energy: A review of key issues and trends shaping integrated community energy systems." Renewable and Sustainable Energy Reviews 56 (2016): 722-744

Luo, Xing, et al. "Overview of current development in electrical energy storage technologies and the application potential in power system

operation." Applied Energy 137 (2015): 511-536. 
Grid in certain (usually rural) areas with weak transmission or distribution connections, connected wind power plants might not be able to operate with the full capacity because of the line and /or transformer overloading. Thus, by deploying ES downstream from regions of congested transmission, the need for more costly transmission and distribution system upgrades can be delayed or entirely eliminated $[84,89,90]$.

\subsection{Other distribution network applications}

RE sources are usually decoupled from the grid by the power electronics devices and in consequence, they do not provide the inertial response in the grid [88]. This influences the electricity system total inertia and in consequence, the grid frequency is more vulnerable to load and generation changes. Moreover, rapid drop or rise in the frequency could cause tripping of generating units or shedding of loads [91].Thus, a fast reacting CES system could quickly deliver or absorb active power in proportion to the time derivative of system frequency and contribute to the grid stability as a result [92]. From a voltage perspective, utilities are trying to maintain voltage within specific limits (mainly in long lines) and this is normally performed by switching capacitors and tap changing of the regulators at the distribution substation [84]. CES systems together with power converters are able to inject and absorb reactive power and contribute to the voltage stability. In the case of power system unavailability, CES systems could also potentially provide black start capability by discharging stored energy for prolonged periods to supply power to specified loads when the grid is unavailable [93]. Additionally, a fast and accurate CES performance is able to eliminate or mitigate power fluctuations (e.g., harmonic signals, spikes and dips in voltage) or power disruptions and provide ride-through capability [91]. CES applications and their requirements are presented in Table 3Table 3.

Besides technical readiness of ES to provide distribution network services, the other important aspect is also the techno-economic viability which, for example, has been studied for different US cities in [ref3]. Moreover, Sardi et al. proposed a strategy for optimal allocation of multiple CES units in a distribution system with photovoltaic generation [ref 4]. The proposed strategy is based on the cost-benefit analysis and it aims for maximizing net present value of the investment. Ho et al. developed recently a tool for optimal scheduling of energy storage in distributed energy generation system by taking into account uncertainty of varying weather conditions [ref 5].
Commenté [MAS2]: Knueven, Ben, et al. "Economic feasibility analysis and operational testing of a community energy storage system." Energy Conversion Congress and Exposition (ECCE), 2016 IEEE. IEEE 2016.

Commenté [MAS3]: Sardi, Junainah, et al. "Multiple community energy storage planning in distribution networks using a cost-benefit analysis." Applied Energy 190 (2017): 453-463.

Commenté [MAS4]: Ho, Wai Shin, et al. "Optimal scheduling of energy storage for renewable energy distributed energy generation system." Renewable and Sustainable Energy Reviews 58 (2016): 1100-1107. 
Table 3: CES application for distribution network applications and electricity markets including their main characteristics [94-97]. Based on IEA data from the Technology Roadmap, Energy Storage (C) OECD/IEA 2014, www.iea.org/statistics. Licence: www.iea.org/t\&c; as modified by University of Geneva and Aalborg University.

\begin{tabular}{|c|c|c|c|c|c|}
\hline Application & $\begin{array}{l}\text { Output } \\
\text { (electrical, } \\
\text { thermal) }\end{array}$ & $\begin{array}{l}\text { Size } \\
(\mathrm{MW})\end{array}$ & $\begin{array}{l}\text { Discharge } \\
\text { duration }\end{array}$ & Cycles & $\begin{array}{c}\text { Response } \\
\text { time }\end{array}$ \\
\hline $\begin{array}{c}\text { Seasonal } \\
\text { storage }\end{array}$ & $e, t$ & $\begin{array}{l}500- \\
2000\end{array}$ & $\begin{array}{l}\text { Days to } \\
\text { months }\end{array}$ & $\begin{array}{c}1 \text { to } 5 \text { per } \\
\text { year }\end{array}$ & day \\
\hline Arbitrage & $\mathrm{e}$ & $\begin{array}{l}100- \\
2000\end{array}$ & $\begin{array}{c}8 \text { hours to } 24 \\
\text { hours }\end{array}$ & $\begin{array}{l}0.25 \text { to } 1 \\
\text { per day }\end{array}$ & $>1$ hour \\
\hline $\begin{array}{l}\text { Frequency } \\
\text { regulation }\end{array}$ & $\mathrm{e}$ & 1 to 2000 & $\begin{array}{c}1 \text { minute to } 15 \\
\text { minutes }\end{array}$ & $\begin{array}{c}20 \text { to } 40 \text { per } \\
\text { day }\end{array}$ & $1 \mathrm{~min}$ \\
\hline Load following & $e, t$ & 1 to 2000 & $\begin{array}{c}15 \text { minutes to } \\
1 \text { day }\end{array}$ & $\begin{array}{c}1 \text { to } 29 \text { per } \\
\text { day }\end{array}$ & $<15 \min$ \\
\hline $\begin{array}{l}\text { Voltage } \\
\text { support }\end{array}$ & $\mathrm{e}$ & 1 to 40 & $\begin{array}{c}1 \text { second to } 1 \\
\text { minute }\end{array}$ & $\begin{array}{c}10 \text { to } 100 \\
\text { per day }\end{array}$ & $\begin{array}{l}\text { ms to } \\
\text { second }\end{array}$ \\
\hline Black start & $\mathrm{e}$ & $\begin{array}{c}0.1 \text { to } \\
400\end{array}$ & $\begin{array}{c}1 \text { hour to } 4 \\
\text { hours }\end{array}$ & $<1$ per year & $<1$ hour \\
\hline $\begin{array}{c}\text { T\&D } \\
\text { congestion } \\
\text { relief }\end{array}$ & $e, t$ & 10 to 500 & $\begin{array}{c}2 \text { hours to } 4 \\
\text { hours }\end{array}$ & $\begin{array}{c}0.14 \text { to } 1.25 \\
\text { per day }\end{array}$ & $>1$ hour \\
\hline $\begin{array}{c}\text { T\&D } \\
\text { infrastructure } \\
\text { investment } \\
\text { deferral }\end{array}$ & $e, t$ & 1 to 500 & $\begin{array}{c}2 \text { hours to } 5 \\
\text { hours }\end{array}$ & $\begin{array}{c}0.75 \text { to } 1.25 \\
\text { per day }\end{array}$ & $<15 \min$ \\
\hline $\begin{array}{l}\text { Demand } \\
\text { shifting \& peak } \\
\text { reduction }\end{array}$ & $e, t$ & $\begin{array}{c}0.001 \text { to } \\
1\end{array}$ & $\begin{array}{c}\text { Minutes to } \\
\text { hours }\end{array}$ & $\begin{array}{c}1 \text { to } 29 \text { per } \\
\text { day }\end{array}$ & $<1$ hour \\
\hline Off-grid & $e, t$ & $\begin{array}{c}0.001 \text { to } \\
0.01\end{array}$ & $\begin{array}{c}3 \text { hours to } 5 \\
\text { hours }\end{array}$ & $\begin{array}{c}0.75 \text { to } 1.5 \\
\text { per day }\end{array}$ & $<15 \min$ \\
\hline RE integration & $e, t$ & 1 to 400 & $\begin{array}{l}1 \text { minute to } \\
\text { hours }\end{array}$ & $\begin{array}{c}0.5 \text { to } 2 \text { per } \\
\text { day }\end{array}$ & $<10 \min$ \\
\hline $\begin{array}{c}\text { Waste heat } \\
\text { utilization }\end{array}$ & $\mathrm{t}$ & 1 to 10 & 1 hour to 1 day & $\begin{array}{c}1 \text { to } 20 \text { per } \\
\text { day }\end{array}$ & $<15 \min$ \\
\hline $\begin{array}{l}\text { Combined heat } \\
\text { and power }\end{array}$ & $\mathrm{t}$ & 1 to 5 & $\begin{array}{c}\text { Minutes to } \\
\text { hours }\end{array}$ & $\begin{array}{c}1 \text { to } 10 \text { per } \\
\text { day }\end{array}$ & $<15 \min$ \\
\hline $\begin{array}{c}\text { Spinning } \\
\text { reserve }\end{array}$ & $\mathrm{e}$ & $\begin{array}{l}10 \text { to } \\
2000\end{array}$ & $\begin{array}{l}15 \text { minutes to } \\
2 \text { hours }\end{array}$ & $\begin{array}{c}0.5 \text { to } 2 \text { per } \\
\text { day }\end{array}$ & $<15 \min$ \\
\hline $\begin{array}{c}\text { Non-spinning } \\
\text { reserve }\end{array}$ & e & $\begin{array}{l}10 \text { to } \\
2000\end{array}$ & $\begin{array}{l}15 \text { minutes to } \\
2 \text { hours }\end{array}$ & $\begin{array}{c}0.5 \text { to } 2 \text { per } \\
\text { day }\end{array}$ & $<15 \min$ \\
\hline
\end{tabular}




\section{Electrochemical energy storage}

\subsection{Lead-acid batteries}

Lead-acid $(\mathrm{PbA})$ batteries are the most mature battery ES technology available on the market since it has been widely used extensively in automotive applications (starting, lighting, and ignition) and battery-based uninterruptible power supplies [9, 32, 98]. From the design perspective, a large variety of $\mathrm{PbA}$ batteries are currently available [99]. Besides their commercial maturity, $\mathrm{PbA}$ batteries are havinghave relatively high efficiency (i.e., $70 \%$ $80 \%$ ), low cost, and long calendar lifetime (i.e., 5 - 15 years) [9, 100]. However, traditional $\mathrm{PbA}$ batteries have a relatively short cycle-lifetime (e.g., $500-2000$ cycles), are not suitable for cycling at partial state-of-charge-(i.e., PbA battery are typically held at full charge between discharges), have a limited charging power capability, and poor performance at low temperatures [9, 32, 98, 101]. Thus, conventional $\mathrm{PbA}$ batteries are less suitable for stationary CES applications-(e.g., CES applisations), where high power capability during charging and discharging, cycle at partial state-of-charge, and long lifetime are required. -To overpass the aforementioned drawbacks, improved advanced $\mathrm{PbA}$ batteries (generically called advanced PbA batteries) were developed and are on the early deployment stage [32, $98,101]$. The most known improvement is the use of carbon, in different forms, in one of both electrodes providing the advanced PbA battery with characteristics similar to those of supercapacitors (at the anode side (Akhil et al., 2013)[101]. Other improvements have considered the use of carbon-doped cathodes, high-density positive active materials, and silica-based electrolytes (Akhil et al., 2013). The structure and features of some of the developed advanced PbA batteries are reported in the literature (Akhil et al., 2013; McKeon et al., 2014, Terada et al. [102] and H. Yoshida et al. [103]. Thus, advanced PbA batteries have reached much highefup to nine times higher power capability (up to nine times) and four to ten times increase in the cycle lifetime (four to ten times) than traditional $\mathrm{PbA}$ batteries, becoming able to provide power peaks and operate for an extended time at partial state-of-charge in CES applications.

\subsection{Lithium-ion batteries}

Even though the first Li-ion batteries were commercialised in the beginning of the 1990s, this battery ES technology has become the fastest growing technology for stationary ES applications in recent years [32] because of their inherent higher gravimetric and volumetric energy density in comparison other traditional batteries (e.g., PbA batteries). First designs were based on graphite and lithium cobalt oxide $\left(\mathrm{LiCoO}_{2}\right)$ as active materials, but currently $\mathrm{Li}$-ion batteries are based on new and/or improved chemistries (e.g., LiFePO${ }_{4}$ and $\mathrm{Li}_{4} \mathrm{Ti}_{5} \mathrm{O}_{12}$ ) [9, 98, 104-106]. These Li-ion batteries are characterised by high gravimetric and volumetric energy density (i.e., 75-200 Wh/kg and 200-500 Wh/L), high efficiency (i.e., 90 - 95\%), high power capability (e.g., up to 9 times the nominal power), long cycle and calendar lifetime (e.g., 8000 full cycles and 20 years), and operation over a wide temperature range (e.g., $20^{\circ} \mathrm{C}$ to $55^{\circ} \mathrm{C}$ ) [9, 32, 104, 107-109]. Nevertheless, each Li-ion battery chemistry has its unique characteristics therefore none of them is capable of offering all the aforementioned characteristics. The final design will be optimised either for power or energy applications [14]. The main drawback of Li-ion batteries is related to their still high cost. As illustrated in Fig. 7Fig. 7, the cost is enhanced by the presence of additional components such as the management system, which ensures the safe operation of the Li-ion batteries (i.e., protection for overcharging, over-discharging, and over-temperature) and cell voltage balancing [12, $100,110]$. However, the cost of the Li-ion batteries is expected to decrease with their manufacturing on a large scale $[32,111]$. Fig. 8Fig. 8 illustrates the dropping price of Li-ion cells including its projection until 2020 for both consumer electronics Li-ion batteries and large format Li-ion cells, which are used in CES applications.- For example, Li-ion batteries

Commenté [DS5]: I think the name of the authors should be removed in order to be consistent with the rest of the paper. 
based on the Nickel Manganese Cobalt chemistry are projected to have a price of 300 US $\$ / \mathrm{kWh}$ by 2020 , the current one being 600 US $\$ / \mathrm{kWh}$ [112].

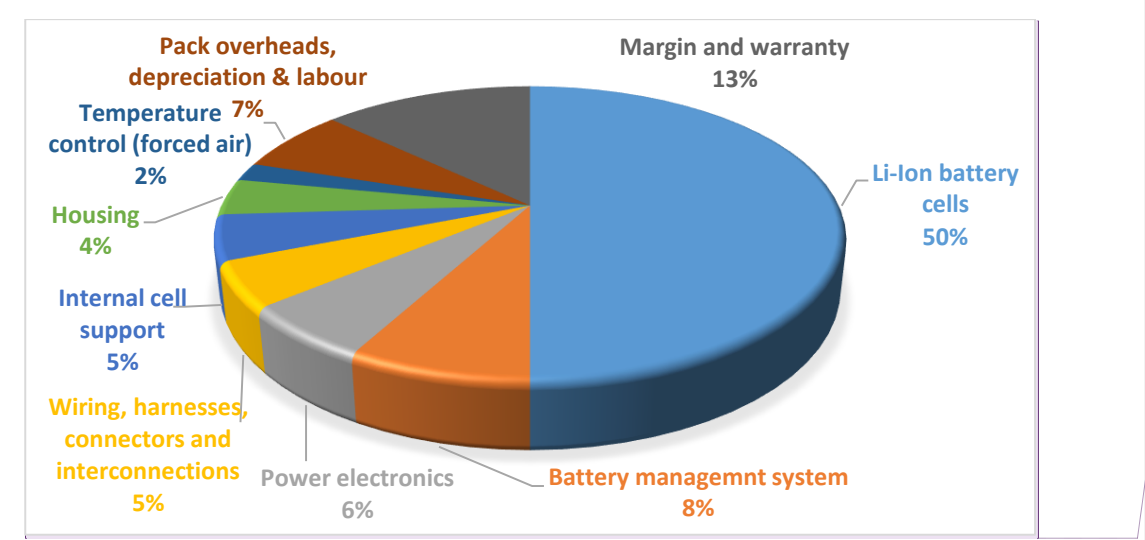

Fig. 7: Total cost breakdown for a 22kWh Li-ion battery pack used in electric vehicles based on data provided by the International Renewable Energy Agency (IRENA) [113].

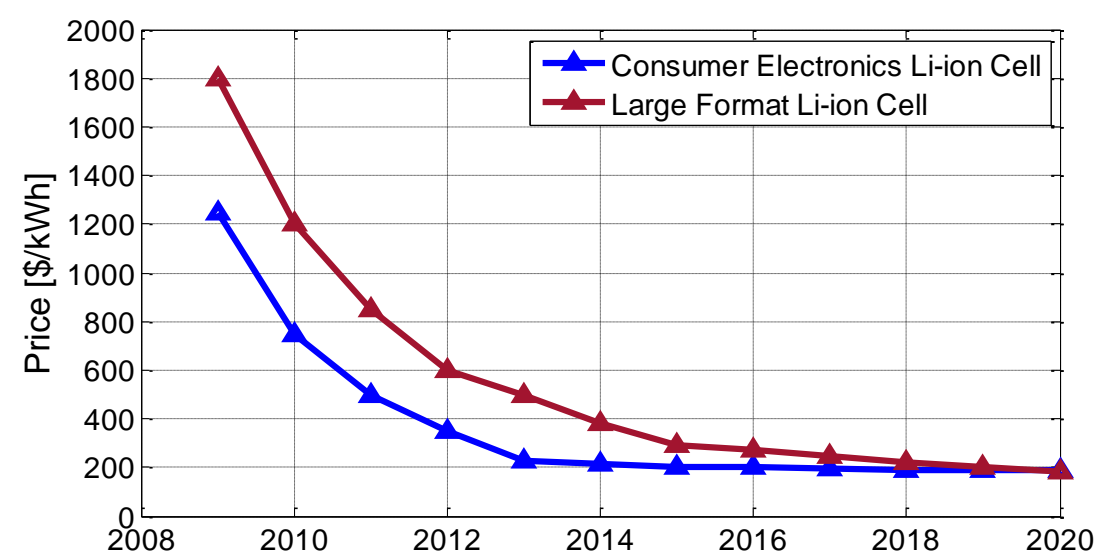

Fig. 8: Forecasted cost decrease (US\$) for Li-ion battery cells based on [111]

Because of their characteristics, Li-ion batteries are suitable for both short-term (i.e., minutes) and medium-term (i.e., up to 4 hours) applications such as frequency regulation, voltage support, peak shaving, REs' grid integration etc. [32, 100]. By the end of 2013 a total of $100 \mathrm{MW}$ grid-connected Li-ion batteries have been installed worldwide for demonstration

\footnotetext{
${ }^{6}$ Waiting for permission from Navigant Research
}

Commenté [d6]: Aalborg->two lines are missing from the pie to "Battery management system $8 \%$ " and "Margin and warranty $13 \% "$ 
and/or commercial purposes [32]; these installations have targeted both distributed systems (e.g., 5-10 kW / $20 \mathrm{kWh}$ ) and larger grid-connected systems (e.g., $1 \mathrm{MW} / 0.25 \mathrm{MWh}$ ) [32].

\subsection{Sodium-Sulphur battery}

Redox flow batteries were firstly described and proposed by Thaller [33] as attractive alternatives for pumped-hydro and PbA battery ES solutions. Because of their features, which are summarized below, fFlow batteries represent a very suitable technology for mid and long term CES applications because of their features, which are summarized below [115-117]. Flow batteries employ two electrolytes (fully soluble redox couples/ electroactive species) that are stored in different tanks and pumped through a microporous membrane (cell stack) in which the chemical energy is converted into electricity $[9,33,100,115]$. Unlike conventional batteries, flow batteries poses the unique advantage of having their power capability and energy decoupled from each other, which allows for a flexible design and easy scale-up [ $[9,32,24,115,117]$; while the power capability is determined by the size of the cell stack, the energy is determined by the volume of the tanks in which the electrolytes are stored and by the electrolytes' concentration [9, 100, 115]. Depending on the considered electrolytes' chemistry, different flow battery technologies have been developed that reached different maturity levels (from large-scale demonstration stage to early development stage), as summarized in Table 4 [9, 32, 100]; this is the case of the vanadium redox battery [34,

Table 4: Main characteristics of different flow battery technologies.

\begin{tabular}{|c|c|c|c|c|c|}
\hline $\begin{array}{l}\text { Technology/ } \\
\text { Properties }\end{array}$ & $\begin{array}{c}\text { Voltage } \\
{[\mathrm{V}]}\end{array}$ & Efficiency & Lifetime & Maturity & Reference \\
\hline $\begin{array}{c}\text { Vanadium- } \\
\text { Redox (VRB) }\end{array}$ & $1.4 \mathrm{~V}$ & $85 \%$ & $\begin{array}{l}10000 \\
\text { cycles }\end{array}$ & $\begin{array}{c}\text { Commercial } \\
\text { available; verified in } \\
\text { field demonstrations }\end{array}$ & $\begin{array}{l}\frac{34,115}{118,119} \\
\underline{18}\end{array}$ \\
\hline $\begin{array}{l}\text { Zinc Bromine } \\
(\mathrm{ZnBr})\end{array}$ & $1.8 \mathrm{~V}$ & $65 \%$ & $\begin{array}{l}2000 \\
\text { cycles }\end{array}$ & $\begin{array}{l}\text { Early stage of field } \\
\text { deployment and } \\
\text { demo trials }\end{array}$ & $\underline{34,117}$ \\
\hline $\begin{array}{l}\text { Polysulphide } \\
\text { Bromine } \\
\text { (PSB) }\end{array}$ & $1.5 \mathrm{~V}$ & $75 \%$ & $N / A$ & $\begin{array}{l}\text { No fully deployed } \\
\text { systems available }\end{array}$ & $\underline{34,117}$ \\
\hline $\begin{array}{c}\text { Iron } \\
\text { Chromium } \\
(\mathrm{Fe} / \mathrm{Cr})\end{array}$ & $\begin{array}{c}0.9-1.2 \\
V\end{array}$ & $70-80 \%$ & $\mathrm{~N} / \mathrm{A}$ & $\begin{array}{l}\text { Early stage of field } \\
\text { deployment and } \\
\text { demo trials }\end{array}$ & $\underline{32,33,116}$ \\
\hline
\end{tabular}

The main advantages of the flow batteries include: long calendar lifetime (i.e., $10-15$ years, depending on technology), high energy capability (i.e., up to 10 hours), no self-discharge (because the electrolytes are stored in separate tanks), fast response (i.e., few milliseconds - if cell stack), deep discharge capability (without safety and lifetime consequences [34, 115$117,119]$. Furthermore, flow batteries allow for a flexible design and easy scale-up since their energy and power are decoupled $[9,32,34,117]$. The main drawback is their complex structure, which can cause reliability issues $[98,100]$.

\subsubsection{Hydrogen}

Hydrogen is considered as a promising form to store energy because of its high specific energy density (33 kWh/kg) and volumetric density (it can be as high as $25 \mathrm{~g} / \mathrm{L}$ when it is 
pressurized to $350 \mathrm{bar}$, or to $70 \mathrm{~g} / \mathrm{L}$ when it is liquefied) [120]. These characteristics together with the decoupling of the power and energy ratings make hydrogen very attractive for midterm and long-term ES. The pathways of using hydrogen as an ES medium in communities are illustrated in Fig. 9Fig. 9. Power-to-gas is not part of this schematic representation and it discussed in this section since it is more economically viable for large scale plants, i.e. several MWs [121].

The first step to store electricity is achieved by electrolysis: when there is excess of electricity generated from RE sources, or electricity at low prices, an electrolyser system splits water into oxygen and hydrogen using DC electricity. There are three types of electrolysis technologies available: alkaline, polymer electrolyte membrane (PEM) and high temperature solid oxide electrolysers [122]. Alkaline electrolysis is the dominant technology in the market today due to its maturity and low cost (525 US\$7/ $\mathrm{kW})$, whereas PEM electrolysis was commercialised at a later stage and offers higher power density (i.e. more compact systems) [123] as well as variable load operation including very low partial operation (5\%). The main disadvantage is still the much larger price of the electrolyser stack due to material costs (e.g., platinum for catalysts), around $1050 \mathrm{US} \$ / \mathrm{kW}$ [124]. Alkaline and PEM are referred to as lowtemperature electrolysis (typical temperatures between $50{ }^{\circ} \mathrm{C}$ and $80^{\circ} \mathrm{C}$ ), and they have efficiencies from $62 \%$ to $82 \%$, which corresponds to 4.5 to $7.5 \mathrm{kWh}$ of electricity consumption per $\mathrm{Nm}^{3}$ of hydrogen production [122]. Solid oxide electrolysis is at the research and demonstration phases given the challenges of corrosion, seals, thermal cycling, and chrome migration, although it has gained more attention recently, because of its more efficient performance (voltage efficiency from $81 \%$ to $86 \%$ ) in comparison with the other two technologies [125] and since it uses no noble metals.

The second step is the storage of hydrogen in a form of gas, liquid or as a metal hydride. When it is stored as gas, it typically requires high-pressure tanks with pressure at 350 bar or 700 bar reducing the round trip efficiency because of the amount of energy required by the compressor. Another alternative is storage of hydrogen as a liquid requiring cryogenic temperatures because of its low boiling point. However, this conversion requires around $30 \%$ of the LHV of the stored $\mathrm{H} 2$ and therefore reduces the round trip efficiency as well. Compressed and liquid storage of $\mathrm{H} 2$ do not offer the potential to meet the gravimetric and volumetric targets for on-board transport applications DOE [126]. And this is the driver for metal hydrides. Metal hydrides are promising means of storing hydrogen for applications with space constraint in terms of their safety condition (moderate temperature and pressure) and low energy to operate, but the current cost of around 5750 US\$/kg [127], and their constraints in weight and space are still the limiting factors for further applications

\footnotetext{
${ }^{7} 1.05$ is the conversion rate assumed between the Swiss franc and the US dollar.
} 


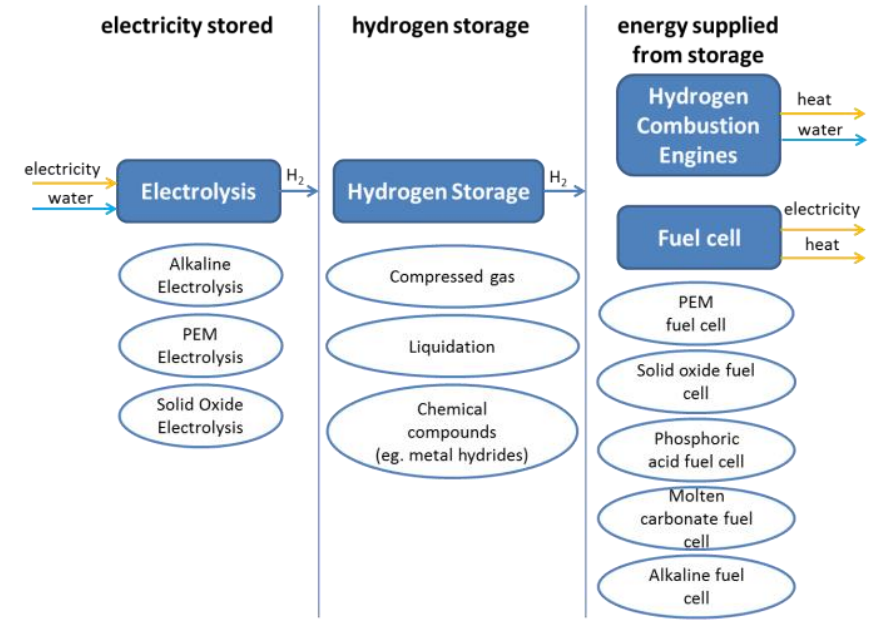

Fig. 9: Pathways using hydrogen as ES with options of different technologies

PEM fuel cells (PEMFCs) and solid oxide fuel cells (SOFCs) are the most common technologies for generating both electricity and heat from hydrogen as combined heat and power (CHP) generators. Main performance differences come from the operational temperature and related materials for the stack, around $80^{\circ} \mathrm{C}$ and $600-800{ }^{\circ} \mathrm{C}$, respectively. As a consequence, SOFCs offer higher electrical efficiency (up to $60 \%$ ) but are less suitable for dynamic response and start-ups [55]. However, PEMFC and SOFC stacks are still expensive, for example $500 \$ / \mathrm{kW}$ and $800 \$ / \mathrm{kW}$ for a $5 \mathrm{~kW}$ system [127]. Overall, a $50 \mathrm{KW}$ fuel cell (FC) system running as CHP has a current cost of 1029250 US $\$$ but mass production and related economies of scale are expected to bring this value down to 115000 US\$ approximately [128].

From an application perspective, some studies were conducted applying hydrogen as CES, with focus on distributed ES systems of relatively small size (20 kWh to $1 \mathrm{MWh}$ ), and storage duration from minutes to months. Steward compared hydrogen and battery storage as CES for a community of 100 residents Steward [129]. It was concluded that the low round-trip efficiency of the hydrogen system $(41 \%)$ causes high penalty in levelised cost of electricity stored compared to batteries. However, hydrogen as ES medium allows to integrate more $\mathrm{RE}$, and has more flexibility than battery in larger systems. Alternatively, a hybrid system comprising a $10 \mathrm{kWh}$ Li-ion battery and hydrogen storage (with a $6 \mathrm{~kW}$ PEM electrolyser) was proposed for a 7-home low carbon community (all houses were assumed to have a 3 kW PV system) as daily and long-time CES, the latter suggested since a seasonal mismatch occurred despite the daily buffer offered a $10 \mathrm{kWh}$ Li-ion battery [55]. It was found that such a hybrid system is able to increase onsite consumption of PV energy, and reduce the electricity export to the grid by $95 \%$ compared to a single home system with the same FC system. Interestingly, a CES system using hydrogen technology was later built and tested when performing PV energy time-shift and demand load-shifting in a real low carbon 7-home community. In this case, mid-term ES was demonstrated when CES performed demand load shifting and hydrogen was stored for use one day later [63].

\subsubsection{Hybrid Energy Storage Systems}

In most energy systems, examination of the load duration curves shows that there are typically a small number of hours each year which have very high or very low extremes of 
demand, with the larger portion of the year exhibiting intermediate load levels. High-power peaks tend to have relatively short duration, and diversity of loads in larger communities tends to flatten the demand curve meaning that extremes of demand are encountered less often, but, importantly, high-power incidents do still occur (see Fig. 3Fig. 3). Installing a system to manage energy and power flows within a community means that the CES system experiences - and can hopefully optimise - the peaks and troughs in demand and supply. However, specifying a CES system which has the capability to manage both peak power requirement $(\mathrm{kW})$ over a few minutes, and has sufficient energy (kWh) to supply the community for a number of hours, would possibly lead to specification of a large battery system which may not actually be economically viable (in an electrochemical battery energy to power ratio is fixed by the type of chemistry). So in some cases it may be better to install a hybrid (multi-technology) ES system, where specific technologies are chosen for either their energy capacity or their high power capability, but act together seamlessly as a single ES system [130].

An example hybrid ES system is shown in Fig. 10Fig. 10, where the power vs. energy for import and export from a community with on-site RE generation are shown with the dotted blue line. If a single ES device was chosen so as to meet both the power and energy requirements, this configuration (the red target symbol) may end up as significantly more expensive than a hybrid ES solution made up of smaller building blocks (in this case three different technologies) which still meet the power and energy requirements for the community. One drawback of this approach is that configuration, optimisation and control algorithms for a hybrid ES system are significantly more complicated than for a singletechnology solution.

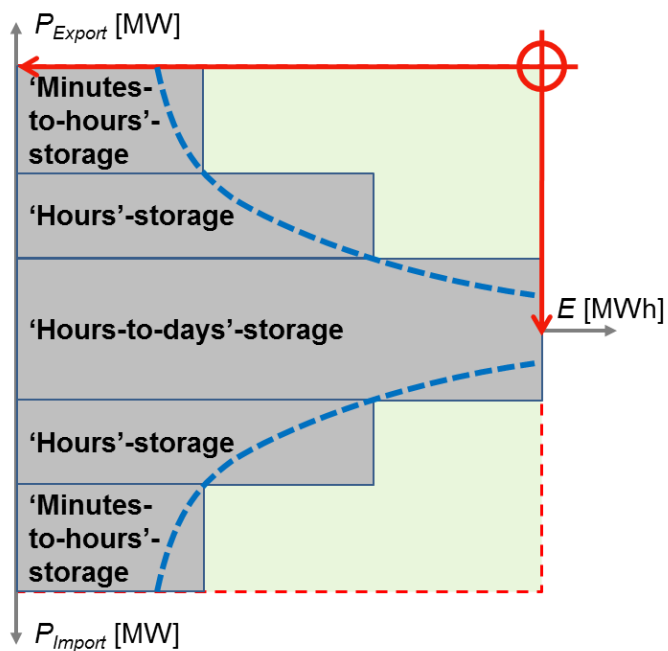

Fig. 10: Diagram showing power and energy charging and discharging requirements for a CES system (blue dotted line); a single CES system which meets these requirements (red target symbol); and a generic hybrid system which also meets these requirements (grey boxes).

Example building blocks to create hybrid systems may be: flywheels or supercapacitors for high-power capabilities; PbA or Li-ion batteries for balanced energy and power; flow-batteries or hydrogen for storage of energy - systems may be built using one or more of these technologies depending on requirements. In this way, the combined performance characteristics of the ES devices can be much more closely aligned with the actual demand curve, so that each device is utilised optimally, and the CES owner does not pay for device 
capabilities that are never used. Typically, the high power capability, short-term ES performs many charge-discharge cycles and so must be a technology with a long cycle lifetime - this tends to be a more expensive technology, but only a relatively small system is required to manage the higher frequency power fluctuations [131]. The longer-duration, lower-power part of the hybrid CES performs far fewer cycles, and hence this can be a low-cost technology focusing on storage of energy over longer time periods.

Operationally, a hybrid CES system is challenging to manage [132], as it consists of multiple devices connected together, each of which have different performance characteristics, voltages, currents, states of charge, and rates of change of these parameters - unlike an ESS made up of modules of the same technology which should all have fairly similar characteristics and can act in unison. Dispatching of the sub-units can be based upon knowledge of the system demand curves and the likely duration of a certain level of power within the system [133]. High charge-rate sub-units should be dispatched to manage highpower, short-duration incidents, whilst low power devices can shift energy around over a period of minutes to hours. Germany is very much leading the way in demonstrating industrial-scale hybrid energy ES systems; key examples include: Braderup-Tinningstedt, Pellworm and M5Bat, which have implemented multiple ES technologies to provide optimised community and system solutions [133].

\section{Thermal Energy Storage}

Thermal energy storage for building heating and cooling purposes comprises several technologies with different characteristics as summarized in Table 5Table 5. The most storage technology is hot water tanks with a temperature in the range of $55-60^{\circ} \mathrm{C}$ (to avoid water bacteria growth). Water tanks are also used for building heating and cooling storage purposes with the advantage that no heat exchanger is required between the storage and the energy carrier, i.e. reducing the exergy losses associated with the heating/cooling system that arises from heat exchange. The use of the storage material as the energy carrier also implies a high storage power to capacity ratio for demand peak shaving. The water tank may also be designed with thermal stratification and several supply ports as to minimise storage mixing losses associated with varying operation temperatures of a solar collector. In the cases of seasonal storage or small differences between supply and return temperatures the drawbacks of a water tanks are the relatively large space requirement and potentially also the cost of the large containers [134].

For a more compact storage design latent heat storage based on PCM may be applied [135], [136]. The heat of fusion of the PCM offers high energy density, for example $310 \mathrm{~kJ} / \mathrm{m}^{3}, 150$ $\mathrm{kJ} / \mathrm{m}^{3}$ and $370 \mathrm{~kJ} / \mathrm{m}^{3}$ for materials such as water, paraffin and salt hydrates, respectively [78]. The material most commonly applied is water/ice technology due to the low cost of the PCM, high heat of fusion and the high thermal conductivity of ice which enhances storage discharge capability. Due to the low phase change temperature, ice/water is mainly used for building cooling and heating applications [74, 75]. The interest in water/ice as a seasonal storage material has however recently increased as an alternative to storage technologies that require deep drilling [137].

The technologies applied for seasonal energy storage are usually based on underground thermal energy storage as large quantities of energy can be stored by using natural materials of low cost (e.g., soil, water, rocks). A common technology for northern and middle European buildings is borehole thermal energy storage in combination with a HP [56]. As the CES is not insulated towards the surroundings the storage temperature should be kept at moderate level (typically below $30^{\circ} \mathrm{C}$ in charged state for a $150 \mathrm{~m}$ deep hole) to avoid significant energy losses and the HP is used to raise the temperature to the required level. A second parameter which affects thermal storages without insulation is the storage volume; thermal losses scale 
with storage surface area and capacity with storage volume which makes larger storages more efficient. Another underground storage technology is the aquifer thermal storage that has reached more than 2'000 installation in the Netherlands [138]. Although this technology has higher energy density (as water is used as storage material) and also potentially lower cost (as few boreholes are required), several geological conditions have to be fulfilled in order for it to be applicable [139], This may limit its maximum technical and economic potential as a result. A shallow underground technology is the pit thermal storage which is an insulated excavation at the surface of the earth that may be filled with water, rock material (gravel), sand or a mixture of these components. It may also have a cover of insulating material for reducing the thermal losses. Several large pit storage projects have recently been proposed in combination with solar thermal collectors supporting district heating networks in Denmark [140]. An overview of different storage technologies for community applications is given in Table 5Table 5.

Table 5: Thermal energy storage systems for community applications based on research experience and some published results [141].

\begin{tabular}{|ccccc|}
\hline $\begin{array}{c}\text { ES } \\
\text { Technology }\end{array}$ & $\begin{array}{c}\text { ES } \\
\text { material }\end{array}$ & $\begin{array}{c}\text { Temperature } \\
\text { level* }\left({ }^{\circ} \mathbf{C}\right)\end{array}$ & $\begin{array}{c}\text { ES time } \\
\text { scale }\end{array}$ & $\begin{array}{c}\text { Energy } \\
\text { density } \\
(\mathbf{k W h} / \mathbf{m} 3)\end{array}$ \\
\hline Aquifer & Soil/Rock/Sand/Water & $5-30^{\circ} \mathrm{C}$ & Months & $30-40$ \\
\hline Borehole & Soil & $5-30^{\circ} \mathrm{C}$ & Months & $15-30$ \\
\hline Latent & $\mathrm{PCM}$ & $0-60^{\circ} \mathrm{C}$ & Hours-Months & $150-310$ \\
\hline Pit storage & Water/Sand/Rock & $5-60^{\circ} \mathrm{C}$ & Months & $10-50$ \\
\hline Water tank & Water/Glycol & $0-60^{\circ} \mathrm{C}$ & Hours-Months & $20-50$ \\
\hline
\end{tabular}

\section{Assessment of CES}

7.1 Techno-economic assessment

The criteria applicable for techno-economic assessment of CES systems (thermal and electricity) include cost, performance and value generation. From a techno-economic perspective, the levelised cost of ES (LCOES) together with the internal rate of return (IRR) and/or net present value (NPV) have been the most commonly used indicators since they quantify the cost and value of the CES discharge using a life-cycle approach [142].

The business case of battery storage for communities strongly depends on both external boundary conditions such as the prices of purchased and sold electricity, tariff structures, etc.; and technology characteristics, e.g., cost (mainly CAPEX), durability and the related ageing. Fig. 11Fig. 11 can be used to further understand the relationship between the IRR and two key parameters, the storage medium cost and electricity prices in the case of Li-ion batteries performing PV self-consumption. The results correspond to a 10-home community in the UK in which 8 homes are assumed to have a $3 \mathrm{~kW} \mathrm{PV}$ installation [21]. For this community, the battery capacity $(42 \mathrm{kWh})$ was optimised in order to maximise the profitability. The reference case is represented by a storage Li-ion medium cost of 1820 US $\$ / \mathrm{kWh}(1300 \mathrm{f} / \mathrm{kWh})$ able to perform up to 3000 equivalent full cycles and a retail electricity price of 0.23 US $\$ / \mathrm{kWh}(16.3 \mathrm{p} / \mathrm{kWh})$.

The relationship is more linear with the electricity price than the storage medium cost but on the other hand the IRR is more sensitive to the storage medium cost. A cost of the storage medium of $360 \mathrm{US} \$ / \mathrm{kWh}$ (260 £/kWh) is the breakeven point for an electricity price of 0.23 US $\$ / \mathrm{kWh}$ (16.3 p/kWh), while $430 \mathrm{US} \$ / \mathrm{kWh}(310 \mathrm{f} / \mathrm{kWh})$ is the breakeven point for an electricity price of $0.27 \mathrm{US} \$ / \mathrm{kWh}(19 \mathrm{p} / \mathrm{kWh})$. When the storage medium cost was 360 US $\$ / \mathrm{kWh}(260 £ / \mathrm{kWh})$, the IRR values were positive for any electricity price projected by 
2020 up to $9.2 \%$ when the electricity price is $0.43 \mathrm{US} \$ / \mathrm{kWh}(31 \mathrm{p} / \mathrm{kWh})$. However, the breakeven point is not reached if the storage medium cost is $1090 \mathrm{US} \$ / \mathrm{kWh}(780 \mathrm{E} / \mathrm{kWh}$, the IRR was $-1.6 \%$ when the electricity price was $0.43 \mathrm{US} \$ / \mathrm{kWh}(31 \mathrm{p} / \mathrm{kWh})$, equivalent to $+90 \%$ in Fig. 11).

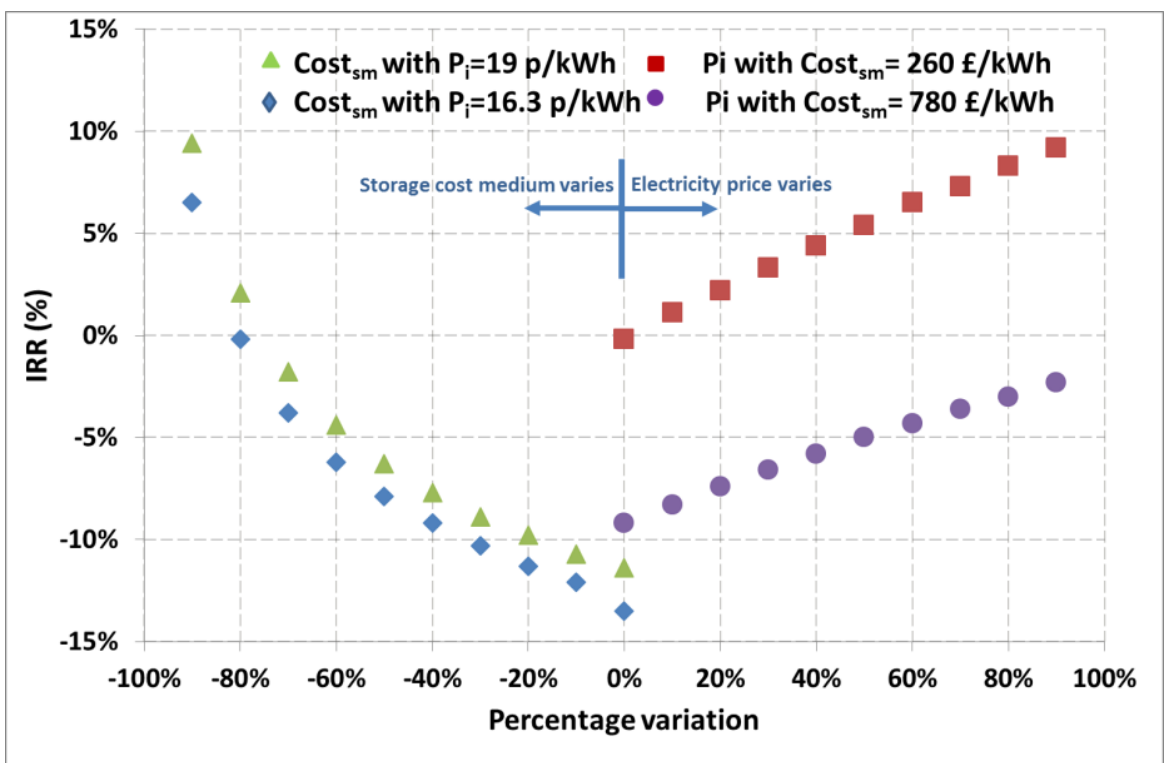

Fig. 11: Internal rate of return (IRR) of the optimum Li-ion battery (42 kWh) performing PV selfconsumpiton in a 10-home community in 2020 (community PV percentage of $76 \%$ ) as a function of the storage medium cost (Cost sm, percentage variation over a reference cost of $1300 £ / \mathrm{kWh}$ equivalent to 1820 US $\$ / k W h$ i.e. $0 \%$ variation) for an electricity price of 0.23 US $\$ / k W h(16.3 \mathrm{p} / \mathrm{kWh}$ ) and 0.27 US\$ $/ \mathrm{kWh}(19 \mathrm{p} / \mathrm{kWh})$; and as a function of the imported electricity price ( $P_{i}$ percentage variation over a reference price of $16.3 \mathrm{p} / \mathrm{kWh}$ equivalent to $0.23 \mathrm{US} \$ / \mathrm{kWh}$ i.e. $0 \%$ variation) for a storage medium cost of 360 US\$/kWh (260 £/kWh) and 1090 US\$/kWh (780 £/kWh).

Regarding thermal storage, the investment of hot water tanks is very sensitive to the difference between the maximum storage and minimum supply temperatures. For example, the investment cost (US $\$ / \mathrm{kWh})$ decreases by a factor of four if the temperature difference increases from $10^{\circ} \mathrm{C}$ to $40^{\circ} \mathrm{C}$ using the same tank. A comparison of total costs of thermal storage (short-term) using a steel tank $\left(95^{\circ} \mathrm{C}, 3 \mathrm{bar}\right)$ in a community is shown in Fig. $12 \mathrm{Fig}$. the case of long-term (seasonal) thermal storage, the size effect on the investment cost is also significant. A comparison of cost data for water tanks, borehole thermal storage (BTES), pit storage and aquifer storage (ATES) is given in Fig. 13Fig. 13. Regarding the value of storage, there have recently been several investigations pointing out the potential benefits in combination with HPs and chillers [77], [143]. It has been estimated that hot water tanks can lead to electricity cost savings in the order of $35 \%$ for residential buildings with HPs if the spot market electricity price is used as a reference [144]. Finally, a comparison between thermal storage and battery storage is possible if the electricity stored is used for driving a HP generating heat as an end product. As pointed out by Blarke et al., thermal storage is currently economically more attractive [145]. 


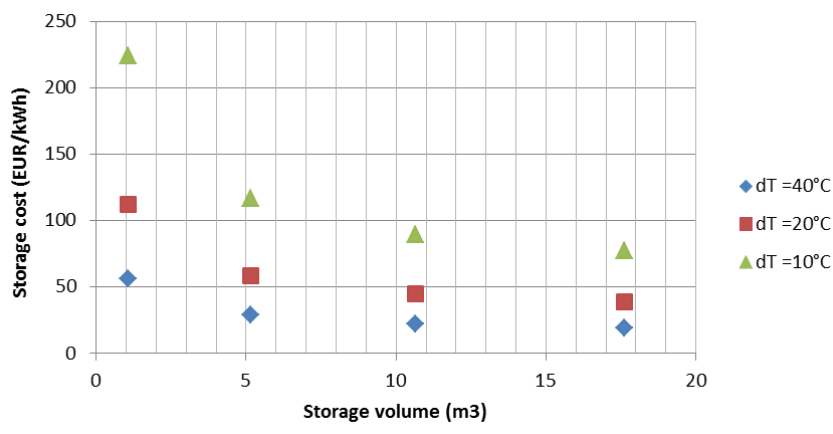

Fig. 12: Investment cost data for steel water tank (incl. thermal insulation) for short-term thermal storage from a Swiss supplier [146].

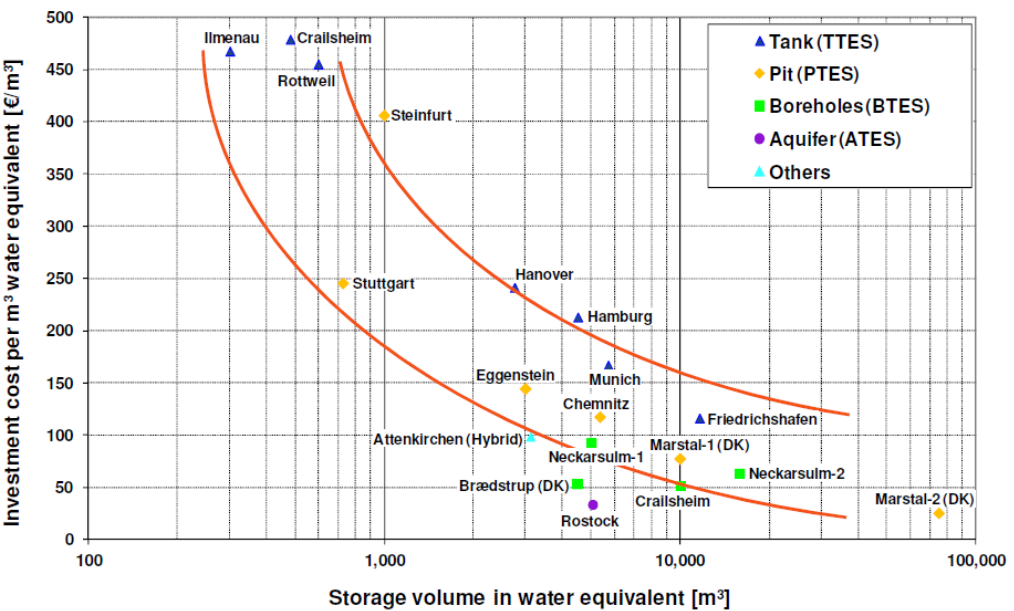

Fig. 13: Investment cost data for seasonal storage technologies, with permission from [139].

\subsection{Socio-economic assessment}

This section discusses the socio-economic implications of CES systems linked with local RE generators. Since the penetration of CES systems faces similar socio-economic challenges to those detected for other distributed energy technologies installed in communities, relevant examples from other technologies are also discussed. Distributed energy generation and storage provide a mechanism to address the issues of affordability of energy supply, energy security and reduction of GHG emissions [20, 147]. The role of economics and project finance is important as CAPEX per unit of energy supplied are relatively high for CES compared to centralised energy systems under current market conditions [20]. In a survey of 132 non-adopters of microgeneration technology in the UK conducted by Caird and Roy [148], the main barriers to uptake were the purchase price $(86 \%$ of the respondents), uncertainty regarding the payback period (68\% of respondents) and size of available grants (60\% of respondents). In a survey of German house owners, Michelsen and Madlener [149] reported that motivational factors varied according to the characteristics of the home owner 
and features of the home. Claudy et al. [150] proposed that reasons against adoption of RE technology have a stronger influence on consumer behaviour than reasons for, and that greater emphasis should be placed on overcoming barriers to adoption of RE as opposed to emphasising reasons for adoption.

While the cost of electricity from PV-coupled battery systems is generally still above that of conventional energy [151], the production and installation costs of distributed ES are expected to continue to decrease in future due to greater expertise, increased productivity and economies of scale (see Fig. 8Fig. 8) [20]. Often community energy initiatives fail due to of long-term resourcing or of long-term supports [152]. In some states in Germany, nearly $40 \%$ of the RE generation is owned by individuals and municipalities [146]. In Denmark, up to $80 \%$ of the offshore wind schemes is characterised by community ownership. By contrast, in the UK community-owned energy schemes constitute approximately $1 \%$ of RE generation [153]. Unlike the UK, countries like Germany and Denmark have a rich heritage of local energy planning where local authorities have traditionally had a strong role in implementing decentralised energy projects [154]. Governments have an important role to play in terms of providing incentives [151], particularly financial. In Germany, in 2013 the government introduced an incentive scheme supporting the purchase of PV-coupled battery systems, covering up to $30 \%$ of the installation costs [155]. Since the scheme was launched uptake has been strong due to the desire for energy independence, and with more than 12,000 storage systems installed by 2015 equipment prices have been falling $[39,156]$.

Shamsuzzoha et al. [157] found that acceptance rates for community RE projects were approximately twice as high as acceptance rates for larger projects in rural Scotland. Community energy projects have the ability to engage the community in energy issues, improve receptivity to RE and engender behaviour change [152]. Bomberg and McEwen [156, p443] argue that motivations for community action on energy issues need to be better understood, and that appealing to a communities' sense of uniqueness, identity and autonomy may be more effective than appealing to a communities' environmental conscience. Heiskanen et al. [158] and Rodrigues et al. [159] suggested that more focus should be placed on the community level and that energy users should be engaged in the role of citizens, and not only that of consumers.

CES can also have positive social implications [20]. Over a two year period the UK Department of Energy and Climate Change (DECC) provided £10 million funding for the installation of low carbon measures in 18 projects throughout the UK as part of the Low Carbon Communities Challenge [160]. Community awareness of local action on energy and climate change increased from $35 \%$ of households to $42 \%$, and positive social outcomes were observed such as further engagement in community groups, associations and communal activities [160]. Community energy projects require interpersonal skills that may be as important as technical skills in overcoming challenges [152].

\subsection{Environmental assessment}

The environmental performance of CES technologies can be assessed using life cycle assessment (LCA), an internationally standardized methodology [161] that considers the environmental burdens of all involved products and services across their life cycles, including raw material production required for $\mathrm{ES}$, storage manufacturing, energy required to deliver the stored energy at a later stage, other operation and maintenance of CES system, as well as the end-of-life of storage equipment, which is often not considered or simplified [162]. LCA assists in identifying opportunities to improve the environmental performance of CES system at various points in their life cycle, and it is usually conducted in four main steps: goal and scope definition; inventory analysis; impact assessment and interpretation. 
Studies that assessed ES technologies using LCA in particular for CES systems are rare. Instead, there has been some research focusing on the assessment of ES in general, or for specific applications, such as load shifting, renewable electricity integration, etc. Most of these studies are for electricity storage, and usually employ the functional unit of $1 \mathrm{kWh}$ of energy stored and supplied from system, and compare it with alternative technologies or baseline system without storage. Some studies use the unit capacity in power or unit weight of storage as functional unit [163], but this is less common. The ES technologies covered usually have a wide spectrum, but mostly fall into the major categories of mechanical storage, electrochemical storage and chemical storage. With regard to impact categories, most studies [164-166] focus on climate change, fossil resource depletion and cumulative energy demand, among which, climate change is the most popular indicator, while other impacts are less discussed.

So far battery technologies have been the most analysed technology, mainly due to their diverse technological variations and wide applications. Some previous studies focused on a specific type of battery (e.g. Li-ion battery, $\mathrm{PbA}$ battery, etc.), and some others compared different types of battery technologies. Most often, application in battery electric vehicles is considered [167-171]. However, battery systems in vehicles could also be applied for stationary applications with only slight technology modification. Sullivan and Gaines [162] reviewed the cradle-to-gate (until the battery is produced and "ready at the gate" of the factory, excluding usage and operation) life cycle inventory of $\mathrm{PbA}$, nickel cadmium, nickel metal hydride, sodium sulfur, and Li-ion batteries. They also pointed out that inventory data for battery recycling are hardly available except for $\mathrm{PbA}$ batteries. Messagie, Oliveira [172] conducted a cradle-to-grave (including usage and operation, as well as the end-of-life fate) LCA study comparing lithium manganese oxide (LMO) battery and lithium iron phosphate (LFP) battery for EV. They found that the environmental performance of Li-ion battery storage systems is overall dependent on its efficiency and directly tied to the origin of electricity input to the battery storage. The temporal and geographical dimension of components production for the battery system can also vary their environmental performance, but differences in environmental impact are mostly observed in the manufacturing and recycling stages of Li-ion batteries. Longo, Antonucci [173] prepared an LCA study comparing sodium and nickel chloride batteries, reaching the conclusion that the manufacture of sodium and nickel chloride batteries contributed more than $60 \%$ of the environmental impact.

Oliveira, Messagie [163] compared the environmental performance of several ES technology applications in Belgium and pointed out that the performance of sodium sulfur battery shows the best environmental performance, and it is followed by molten salt battery, while the combination of electrolyser with a hydrogen operated FC performs worst. Denholm and Kulcinski [174] concluded that, although ES increases the input energy to produce electricity, the life cycle GHG emissions of storage systems when coupled with nuclear or RE sources is less than 400 tonnes $\mathrm{CO}_{2}$ eq./GWh, which is substantially lower compared to the emissions of electricity produced from fossil fuels: between 475 and 1300 tonnes $\mathrm{CO}_{2}$ eq./GWh.

LCA of thermal ES are less discussed in the literature, and are mostly focused on sensible heat storage using hot water [175-177], while sensible heat storage using other media (such as molten salt), and latent heat storage using PCM are less explored. Oró, Gil [178] studied three thermal energy storage systems using different sensible and latent heat storage, analyzed if the energy savings achieved by stored heat are enough to balance the environmental impact produced during the manufacturing and operation phase of each ES system, and found that thermal ES using high temperature concrete shows the lowest life cycle impact. 


\section{CES perspectives and outlook}

\subsection{CES Demonstration projects}

To date, projects involving CES have tended to be at the level of a few tens of consumers at most, driven by DSOs wishing to demonstrate the novel possibilities for ES technologies in their networks, and often seeking to influence regulators to clarify whether DSOs can own/operate ES assets; DSOs are typically forbidden in regulated markets to own/operate 'generation' assets to prevent them from competing against independent generators in the wholesale electricity markets. Example projects include the McAlpine CES systems in Charlotte, North Carolina [179, 180]. However, one of the most extensive demonstration projects to date has been the American Electric Power (AEP) "gridSMART" project in Ohio, deploying a fleet of eighty $25 \mathrm{~kW} / 25 \mathrm{kWh}$ CES units (totalling $2 \mathrm{MW}$ ) on a single $13.2 \mathrm{kV}$ feeder [181]. The CES units provide local voltage-support and islanding capability for groups of customers, whilst also providing utility-scale benefits through aggregation of the devices via a 'Distributed Energy Management' (DEM) controller. A list of these and other CES projects, together with the technologies and battery sizes employed, is given in Table 6Table

Table 6: Summary of current CES projects and demonstrations showing the main characteristics.

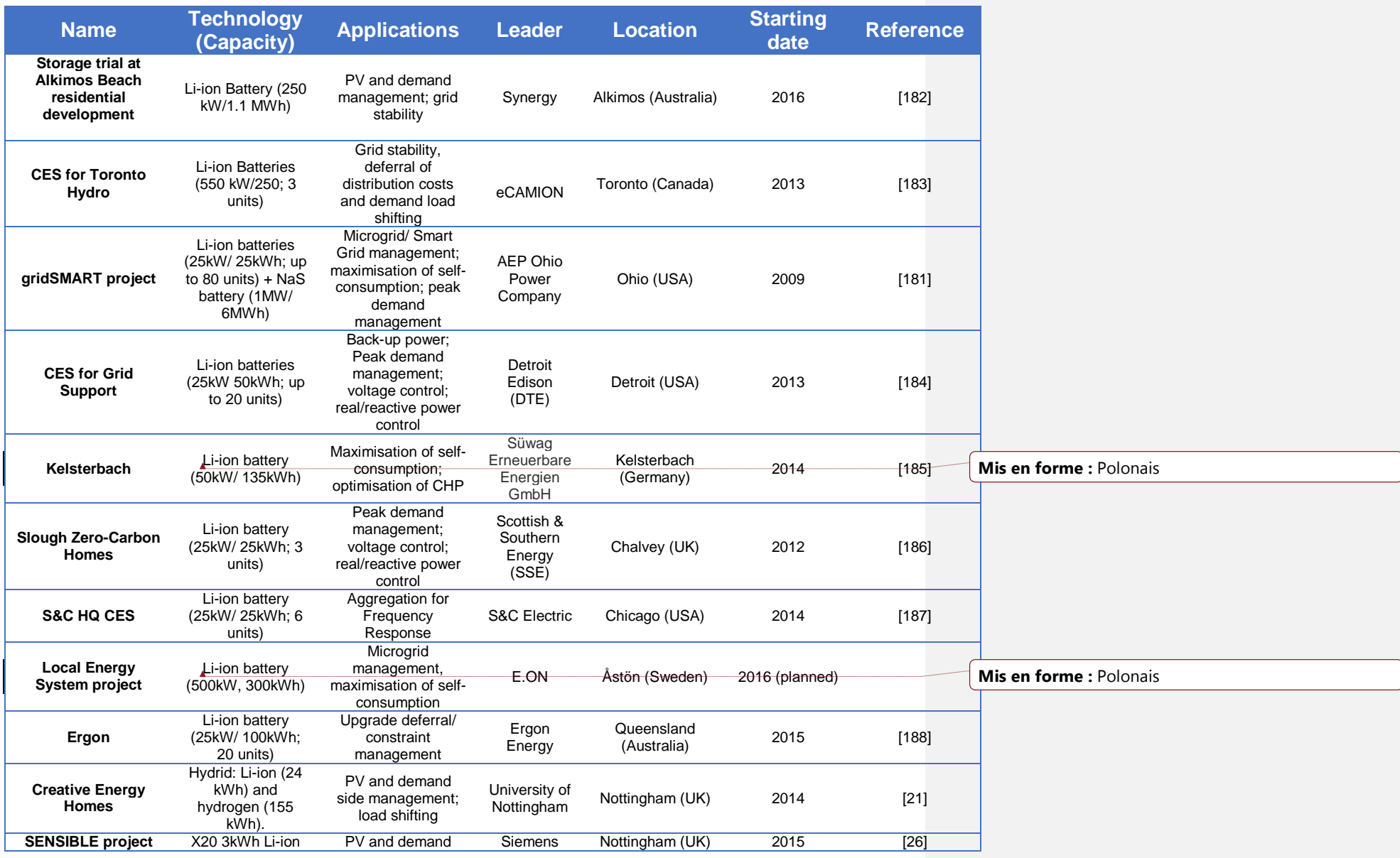




\begin{tabular}{|c|c|c|c|c|c|c|}
\hline & $\begin{array}{l}\text { and } x 220 \mathrm{kWh} \\
\mathrm{PbA} \text { batteries }\end{array}$ & $\begin{array}{l}\text { side management; } \\
\text { grid stability; load } \\
\text { shifting; cost } \\
\text { reduction }\end{array}$ & & & & \\
\hline $\begin{array}{l}\text { McAlpine Circuit } \\
\text { CES System }\end{array}$ & $\begin{array}{l}\text { Lithium Polymer } \\
\text { Battery } \\
(50 \mathrm{~kW} \times 1 \mathrm{~h})\end{array}$ & $\begin{array}{l}\text { transformer-level } \\
\text { peak shaving by } \\
\text { integrating with } \\
\text { residential level } \\
\text { distributed } \\
\text { resources and loads }\end{array}$ & $\begin{array}{l}\text { Duke } \\
\text { Energy }\end{array}$ & Charlotte (USA) & 2011 & [189] \\
\hline INGRID & $\begin{array}{c}\text { Hydrogen } \\
\text { pressurized } \\
\text { electrolyser (500 } \\
\text { kW), pressure } \\
\text { hydrogen storage } \\
\text { tanks ( } 1350 \mathrm{~kg}, 31 \\
\text { bar) }\end{array}$ & $\begin{array}{l}\text { Storage of wind } \\
\text { power }\end{array}$ & Enertrag AG & $\begin{array}{l}\text { Prenzlau } \\
\text { (Germany) }\end{array}$ & 2011 & [190] \\
\hline $\begin{array}{l}\text { Crailsheim } \\
\text { community }\end{array}$ & $\begin{array}{l}40 \mathrm{~m} 3 \text { hot water } \\
\text { storage \& helical } \\
\text { ground heat } \\
\text { exchangers }\end{array}$ & $\begin{array}{l}\text { Building heating } \\
\text { (seasonal storage) }\end{array}$ & $\begin{array}{l}\text { Baden- } \\
\text { Württember } \\
\mathrm{g}\end{array}$ & $\begin{array}{l}\text { Crailsheim } \\
\text { (Germany) }\end{array}$ & 2014 & [71] \\
\hline Suurstoffi & $\begin{array}{l}\text { Borehole heat } \\
\text { exchangers }\end{array}$ & $\begin{array}{l}\text { Building heating } \\
\text { (seasonal storage) }\end{array}$ & $\begin{array}{l}\text { University of } \\
\text { Lucerne }\end{array}$ & $\begin{array}{c}\text { Rotkreuz } \\
\text { (Switzerland) }\end{array}$ & 2012 & [191] \\
\hline La Cigale & Ice storage & $\begin{array}{l}\text { Building heating } \\
\text { (seasonal storage) }\end{array}$ & $\begin{array}{c}\text { SIG, } \\
\text { University of } \\
\text { Geneva }\end{array}$ & $\begin{array}{c}\text { Geneva } \\
\text { (Switzerland) }\end{array}$ & 2010 & [74] \\
\hline
\end{tabular}

\subsection{End users perspective}

The role that end users play in the energy system has changed over the last decades and it continues to evolve. The increasing cost of energy firstly in the seventies and especially in recent years together with minimum energy efficient standards and related incentives have made customers pay more attention to energy efficiency measures to reduce their bills (e.g., refurbishment of their homes with better insulated envelopes, more efficient appliances and related controls). However, the development of more efficient and less costly small-scale technologies such as solar PV and solar thermal energy have been the main reasons for the changing role of customers in the energy system. The end users' requirements and their interests are evolving as the energy system does and they require new services but they also want to play a more active role, as summarized in Table 7 Table 7 . Some examples which illustrate the new position of end users are the increasing number of grassroots or bottom-up initiatives as well as top-down policies for low-carbon communities across many countries [192]; new applications for mobile phones, PCs and tables which allow end users to monitor their energy generation and demand, amongst others; and the proliferation of R\&D projects including end users as a research topic and/or project partners [193] and the first CES business cases sharing end users, utility companies and/or aggregators [194].

Table 7: Different objectives for end users in the context of the energy transition.

\begin{tabular}{|c|}
\hline Customers ' energy objectives \\
\hline Reducing their energy bills or keep them at similar levels \\
\hline Generate and manage their own energy \\
\hline Reduce their carbon footprint \\
\hline Secure of supply guarantee \\
\hline Monitoring and managing their own demand to take decisions in real-time \\
\hline
\end{tabular}

Although these new requirements may be seen as challenging for generators, utility companies and governments, they can also be considered as potential opportunities. Given the wide range of service, economic and environment benefits introduced by CES systems stronger interaction amongst different stakeholders is advised in order to engage the maximum number of customers and advance in the energy transition as a result. Regarding the CES investment, two different options could be considered next to hybrid systems: (a) 
end users purchase a CES system which is connected with their RE generators; (b) or a different party, e.g., utility company, aggregator, energy service company (ESCO) and building service company purchases a CES system in order to manage the energy generated by the RE plants of end users. The first option would promote autarky in a future smart energy system while the second option should at least assure that energy bills are attractively reduced for end users. In this context, the development of new policies and business models including different services provided by CES (see Sections 4-5) and creating win-win situations for customers (who generate their own energy locally) and other stakeholders should be pursued.

\subsection{Utility perspective}

As the level of installed distributed RE generation increases, the requirement for - and economic case of - CES improves [22]. Technology improvements driving down the cost of both generation technologies and battery systems, plus an increasing focus on environmental concerns, localism and community engagement, should all help to significantly enhance the uptake of microgrid and community energy schemes. Most of these schemes will benefit from the installation of technologies to deliver system flexibility, and so it is likely that CES acting in conjunction with demand-side response will play a major part in many projects at this scale. As discussed in this manuscript, benefits of CES are split across the value chain, and effective monetisation of these multiple value streams will be key to implementing viable projects in the early stages.

CES is likely to be provided by house-builders, PV installers, utilities and DSOs (or third parties supplying them storage as a service): some benefits will accrue to householders through lower bills or reduced service charges, etc., but the CES owners and DSOs will also wish to see financial benefits. The business models have yet to be fully developed, but some of the biggest challenges lie around accessing and monetising the multiple value streams, ensuring that all parties are able to clearly see the value, and pay and be remunerated for the benefits CES brings. Ownership models are one of the key enablers for CES: the owner/operator has to be able to balance likely costs and revenue streams over the lifetime of the asset in order to build a business case upfront for construction of the asset. If costs and revenue streams are too low, uncertain, or spread across too many sources, then the uncertainty in the business case may make such projects unviable. Conceivable ownership models run from "Merchant Services" (where e.g. the DSO builds, owns and operates the asset and has full operational control), through to "Contracted Services" (where a long-term contract is offered for $3^{\text {rd }}$-party provision and operation of a storage asset based on price or other control signals) [195]. There are advantages and disadvantages to each approach, plus the balance of risk needs to be considered between the recipient and the provider of the service. At this time, the relative merits of the various ownership models are being investigated through demonstration projects and industry consultations, whilst Regulators are defining the legislative landscape to enable new business models to flourish in the next few years.

In many markets across the world, distribution grids are owned by regulated monopolies, who - in order to avoid potential conflicts of interest - are not also allowed to own generation assets. Hence DSOs are not normally permitted to own (large numbers of) electrical storage systems connected to their network, despite the fact that some of the benefits of embedded ES assets could accrue to them (to name a few: grid investment deferral, power quality, and feeder voltage regulation, for example). In terms of growing the market, there are strong synergies between EV take-up and CES roll-out [196]. Major Li-ion battery manufacturers have in recent years invested heavily in cell-production capacity across the world to gear up for EVs, and the resultant product enhancements, competition and over-supply in the market is rapidly driving down the price of Li-ion modules (see Fig. 8Fig. 8), providing an opportunity other users of the technology to benefit, such as stationary battery suppliers. In terms of 
specific synergies between EVs and CES markets, both require similar sized battery packs (a few tens of $\mathrm{kWh}$ ), and there is the potential also to utilise the high remaining capacity (perhaps $70-80 \%$ of initial capacity) available in end-of-life EV battery packs, in a second life as a cheaper source of stationary electrical storage.

\subsection{Policymakers perspective}

Widespread public support for RE measures has given policymakers the impression that public acceptance is not an issue, however, the evidence suggests there are problems when moving from the global to the local levels [197]. Prasad et al [27] argue that CES (and other distributed energy technologies) can only have a significant roles in future energy systems if all different actors, including local authorities and the government, are on board. Stephen Hall and Katy Roelich [198] describe four steps to achieve greater penetration of distributed energy schemes, these include better routes to market, increased tariffs for exported electricity, closer matching of energy supply and demand, and re-localising energy values.

Schemes such as FITs are an effective method for accelerating the growth of RE technologies [199], Germany and Denmark have a long history of investment in FITs and development of RE [200]. The UK government has proposed cuts of up to $87 \%$ to the generation FITs (in contrast to the export tariff) for solar PV in an effort to reduce costs to the consumer from government energy policies [201], these cuts will undoubtedly adversely affect investment in solar PV and battery storage as a result. In addition, the complexity of the UK state support system is an inhibiting factor in local ownership of energy projects [202]. Other types of taxes and levies can also impact the diffusion of CES schemes. For example, in Germany taxes and levies need to be paid on electricity feeding in to the national grid by CES systems [203-205]. Communities which are embedded in a single building (e.g., block or flats) or alternatively new developments where the grid is privately owned have a significant advantage over disaggregated communities in this regulatory environment.

According to Stephen Hall and Katy Roelich [198] the complexity of the local energy sector is such that even specialists are sometimes unsure of policy, regulatory and market aspects of distributed energy. Therefore, there is a need for a shared learning platform in order to provide policy and regulatory advice. Intermediaries play an important role in creating links between projects and in creating shared infrastructure to support the development of the sector and diffusion of knowledge [206], for example, Community Energy Scotland and Community Energy England [207] provide advice to community energy groups, administer grant schemes and regional specific funds, help prepare funding applications and provide networking opportunities [156]. Bomberg and McEwen [156] attempted to identify factors encouraging community mobilisation, their analysis found that state support was a crucial factor, but it was partially offset by entrenched political and economic interests and closed policymaking. Successful community mobilization depends on how well groups exploit state resources and overcome these barriers.

Small to medium sized schemes find it hard to compete with large energy providers [198]. Energy Service Companies (ESCOs) are companies created to produce and manage the local delivery of energy. ESCOs have the potential to achieve scale economies, for example, ESCOs may obtain discounts for the purchase of energy, reduced staff and material costs and reduced purchase price for equipment [208]. The extent to which costs can be reduced for a particular energy stream depends on the technical potential for improved conversion and distribution of energy [208]. The ESCO model has similarities with other forms of outsourcing and private investment in public infrastructure [208].

There is an incentive for the ESCO to produce and manage energy as efficiently as possible since it is usually the ESCO and not the customer that bears the cost of inefficiency, unlike 
energy utilities which sell units of electricity and the customer bears the cost of inefficiencies [154]. Long-term commitment by governments to the ESCO concept is key. Energy Efficiency and Sustainable Energy Action Plans that do not depend on political election cycles can act as a vehicle for promoting ESCOs, in Denmark a strong energy efficiency regulatory framework has been linked to a commitment to the ESCO model by local administrations [209]. A supportive policy framework and dedicated ESCO legislation and measures such as ESCO standards, certification schemes and financial supports are key success factors, for example, in Spain and Sweden changes to procurement laws have opened the market for long-term energy performance contacts [209].Discussion and

\section{conclusions}

End user applications, namely PV self-consumption, load shifting and demand management including electricity, heat and cooling are driving the penetration of CES. In contrast to other potential applications also performed by CES systems which are considered to be 'power' applications (e.g., voltage control and power quality), these are 'energy' applications, i.e. cycles last for several hours and they are performed on a daily basis. Compared to ES assets at other scales, CES can be i) more effective in (dynamically) balancing local supply and demand than, for example, ES connected to the transmission network; and ii) more costeffective than ES located in single dwellings.

From a CES application perspective, managing PV generation adds more value (and potentially more profitability) than performing demand load-shifting since the difference between the purchased (retail electricity price) and sold electricity price (wholesale electricity price) is higher than the difference between peak and off-peak retail prices. On the other hand, the levelised cost of CES systems could potentially be reduced when shifting the demand load since daily demand requirements are greater than surplus PV energy. However, CES systems using battery technology and only performing end user applications are not profitable yet mainly because of the high cost of the technology. Therefore, these 'energy' applications should be complemented with other services based on the power capability of CES systems. For example, smoothing both the PV power export and electricity grid import is becoming more relevant as the penetration of PV systems, HPs and EVs continues to increase. Additional value can be created by CES systems if capacity tariffs form part of a customer's bill. Furthermore, participation in ancillary services markets (e.g., frequency control) and/or distribution network applications (e.g., distribution network capital deferral) could also be included in the CES value proposition.

Given its high round trip efficiency ( $90 \%$ approximately) and suitability for short-term and mid-term storage cycles, Li-ion battery technology is expected to become the most widespread electrochemical technology for CES systems. This will be driven by strongly reducing Li-ion module prices (for example, from $600 \$ / \mathrm{kWh}$ in 2014 to $300 \$ / \mathrm{kWh}$ predicted by 2020 for Li-ion batteries based on Nickel Manganese Cobalt chemistry). Flow batteries are an attractive solution for mid-term CES applications despite their lack of maturity because of their unique characteristic of decoupled energy and power rating. When disregarding capacity tariffs, $\mathrm{PbA}$ batteries are presently more competitive than Li-ion batteries for demand load shifting (with the battery capacity sized according to the demand load occurring at peak time). However, Li-ion batteries are more economically viable for PV self-consumption (with the battery sized according to surplus PV generation requirements) and demand peak shaving. As the penetration of RE and low carbon technologies increases during the energy transition, it is expected that hybrid systems (comprising different types of electrochemical technologies, e.g., supercapacitors, Li-ion batteries, flow batteries and/or hydrogen) may be required for some communities or districts in order to cover the full 
spectrum of applications, to meet the associated storage cycles with different temporal scales (from seconds to weeks or months).

Thermal storage will continue to be the most utilised CES solution for the next decade given the dominance of space heating and DHW demand in the final energy consumption across many countries with temperate climates and taking into account its cost competitiveness (the CAPEX of thermal storage with hot water tanks, $57.5 \mathrm{US} \$ / \mathrm{kWh}$, is for example still one order of magnitude lower than that of Li-ion batteries). An increased use of thermal storage is also expected for power to heat applications (HPs, CHPs and chillers) and for managing stochastic solar and wind energy. At the same time, seasonal thermal CES solutions are required to mitigate the seasonal variability of the electricity output from these energy sources. As thermal storage gains importance, the penetration of new thermal storage concepts with enhanced energy density such as PCMs is expected to increase.

There are several benefits related to the community approach. From a technical point of view, the aggregation of demand profiles results in a less spiky overall profile in comparison with a single house and this reduces the required discharge rate (relative to the battery capacity). This reduction increases the round trip efficiency and equivalent full cycles of electrochemical storage technologies. The levelised cost, value and profitability associated with end user applications also improve due to better utilisation and performance. From a CAPEX point of view, economies scale are, however, only expected for bi-directional inverters, balance-of-plant installation and maintenance which account only for around $20 \%$ $50 \%$ of the final cost depending on the battery chemistry and final design (i.e. no economies of scale can be realized for the battery cells). However, a community battery system could approximately halve the optimum capacity in comparison with an individual residential battery system due to the positive effect of the aggregation of demands. Economies of scale are also important for different thermal CES solutions.

Regarding the environmental impact of CES systems, the development and use of a more consistent and unified methodology for environmental evaluation of CES is needed in order to perform cross comparison amongst various technologies and applications. LCA is being recommended as the most comprehensive method at the moment, but different methods are still used; and often, system boundaries and functional units of storage systems also vary. Additionally, the results of LCA should be integrated with the techno-economic performance in order to bring environmental considerations into the decision-making process and system designs. From a socio-economic perspective and in combination with distributed wind and solar power generation, CES provides a mechanism to address the issues of affordability, energy security, and energy efficiency and consequently contribute to a reduction of GHG emissions associated with individuals and communities. Importantly, it also provides opportunities for further engagement of individuals in community activities, and the potential to increase awareness of energy and environmental issues. Uptake may be increased if more focus is placed on ensuring that energy users are engaged in CES as citizens, and not only that of consumers.

Regarding the ownership and related location of CES systems, different solutions may coexist. CES systems can be offered by PV installers and/or house-builders therefore installed in different communities (e.g., block of buildings) and paid by end users. Alternatively, they can be operated and/or provided by utility companies and DSOs while being connected to the RE plants and demand loads of the residential sector. The low voltage side of the utility transformers is already being used for the latter case in USA. Regardless of the type of ownership model, CES investments should be profitable but also associated business models should develop win-win solutions for different stockholders involved in the CES project and avoid free riders. Two examples of win-win solutions 
discussed in this manuscript are: (a) electricity tariffs with capacity components for both electricity import and export; and (b) shared business and/or ownership models (including both CAPEX and OPEX) when the value propositions include applications which benefit different stakeholders. For example, the optimum management of local PV generation benefits both the end user (e.g., self-consumption is driven by the difference between the import and export electricity prices), and the utility company and/or DNO (e.g., the deferral of distribution network investment). Moreover, utility companies could also benefit from optimising the performance of CES systems for the electricity network and/or wholesale markets. Likewise, hierarchical control techniques including both the community level, upper level (e.g. distribution network and/or wholesale market) and maintenance should be applied by the utility company (or aggregator).

CES will have a significant role in future energy systems if all different actors, including local authorities and the government, are on board. Uptake may also be enhanced through financial incentives and regulatory frameworks established by policymakers. Similar to other low carbon technologies such as PV and heat pumps, CES diffusion across different countries will have a strong dependence on the regulatory context. The experience from countries such as Denmark and Germany suggest that the success of CES depends on: citizen engagement coupled with access to incentives, community rights over local grid ownership, good management of energy generation and a stable policy support at the community level. In addition, a simplification of the complex regulatory framework around energy is needed to make it accessible to communities and communities' champions. A supportive policy framework and dedicated ESCO legislation and measures such as ESCO standards, certification schemes and financial supports could be key to the success of CES. While creating similar benefits as ES implemented at the level of individual end users (e.g. in private homes, apartment buildings or commercial buildings), the advantages of CES are improved economies of scale (especially in aspects such as power electronics, communications and control technologies) and the option of professional management as well as system benefits at the level of the distribution grid. Last but not least, the community scale has proven to be a catalyst for the engagement of citizens in the energy transition in order to build a sustainable future, i.e. speed up RE penetration, increase energy awareness and reduce the carbon footprint of communities.

\section{Acknowledgements}

This work was funded by the Commission for Technology and Innovation in Switzerland (CTI) within the Swiss Competence Centre for Energy Research in Heat and Electricity Storage (SCCER-HaE), contract number 1155000153. The authors would like to acknowledge The Danish Council for Strategic Research for sponsoring the Advanced Lifetime Predictions of Battery Energy Storage (ALPBES) project and the EU for funding part of this research via the 'Transitioning towards Urban Resilience and Sustainability' TURAS project (Grant No 282834).

\section{Bibliography}

1. International Energy Agency, I., Medium-Term Renewable Energy Report 2015. 2015.

2. International Renewable Energy Agency, I., Renewable Energy Integration in Power Grids. Technology Brief. 2015.

3. Change, D.o.E.a.C., Weekly solar PV installation and capacity (Registration date)- Week ending 30th March 2014, in Month. 2014: https://www.gov.uk/government/statistics/solarphotovoltaics-deployment.

4. (BMWI), B.f.W.u.E., Marktanalyse Photovoltaik-Dachanlagen 2015, Bundesministerium für Wirtschaft und Energie (BMWI).

\begin{tabular}{|l|}
\hline Mis en forme : Danois \\
\hline Code de champ modifié \\
Mis en forme : Danois \\
Mis en forme : Danois
\end{tabular}


5. Arts, L.U.o.A.S.a., IEA HPP Annex 42: Heat Pumps in Smart Grids Task 1: Market Overview Switzerland. 2014, Fraunhofer ISE.

6. ISE, F., IEA HPP Annex 42: Heat Pumps in Smart Grids Task 1: Market Overview, Germany. 2014, Fraunhofer ISE.

7. Tanaka, N., Technology roadmap: Electric and plug-in hybrid electric vehicles. International Energy Agency, Tech. Rep, 2011.

8. Ibrahim, H., A. Ilinca, and J. Perron, Energy storage systems-characteristics and comparisons. Renewable and sustainable energy reviews, 2008. 12(5): p. 1221-1250.

9. Chen, H., et al., Progress in electrical energy storage system: A critical review. Progress in Natural Science, 2009. 19(3): p. 291-312.

10. Huggins, R., Energy storage. 2010: Springer Science \& Business Media.

11. Brunet, Y., Energy storage. 2013: John Wiley \& Sons.

12. Díaz-González, F., et al., A review of energy storage technologies for wind power applications. Renewable and Sustainable Energy Reviews, 2012. 16(4): p. 2154-2171.

13. Cabeza, L.F., et al., Materials used as PCM in thermal energy storage in buildings: a review. Renewable and Sustainable Energy Reviews, 2011. 15(3): p. 1675-1695.

14. Stan, A.-I., et al. Lithium ion battery chemistries from renewable energy storage to automotive and back-up power applications-An overview. in Optimization of Electrical and Electronic Equipment (OPTIM), 2014 International Conference on. IEEE.

15. Niaz, S., T. Manzoor, and A.H. Pandith, Hydrogen storage: Materials, methods and perspectives. Renewable and Sustainable Energy Reviews, 2015. 50: p. 457-469.

16. Lyons, P., et al., Design and analysis of electrical energy storage demonstration projects on UK distribution networks. Applied Energy, 2015. 137: p. 677-691.

17. Zakeri, B. and S. Syri, Electrical energy storage systems: A comparative life cycle cost analysis. Renewable and Sustainable Energy Reviews, 2015. 42: p. 569-596.

18. Group, S.E.S.I., The role of Community Energy Systems in the UK Resilient Energy Supply. 2013, Technology Strategy Board.

19. Klein, S.J. and S. Coffey, Building a sustainable energy future, one community at a time. Renewable and Sustainable Energy Reviews, 2016. 60: p. 867-880.

20. Rae, C. and F. Bradley, Energy autonomy in sustainable communities-A review of key issues. Renewable and Sustainable Energy Reviews, 2012. 16(9): p. 6497-6506.

21. Parra Mendoza, D., Optimum community energy storage for end user applications. 2014, University of Nottingham.

22. Parra, D., et al., Optimum community energy storage system for PV energy time-shift. Applied Energy, 2015. 137: p. 576-587.

23. Arghandeh, R., et al., Economic optimal operation of Community Energy Storage systems in competitive energy markets. Applied Energy, 2014. 135: p. 71-80.

24. Dóci, G. and E. Vasileiadou, "Let' $s$ do it ourselves" Individual motivations for investing in renewables at community level. Renewable and Sustainable Energy Reviews, 2015. 49: p. 4150.

25. van der Schoor, T. and B. Scholtens, Power to the people: Local community initiatives and the transition to sustainable energy. Renewable and Sustainable Energy Reviews, 2015. 43: p. 666-675.

26. O'DOHERTY, T., RODRIGUES, L, GILLOTT, M, The Role of Community-based Energy Management Schemes in Supporting Resilience". In: Rodrigues, L. ed. Sustainable Energy for a Resilient Future, in Sustainable Energy Technologies 2015: Nottingham (UK).

27. Koirala, B.P., et al., Energetic communities for community energy: a review of key issues and trends shaping integrated community energy systems. Renewable and Sustainable Energy Reviews, 2016. 56: p. 722-744.

28. Zhu, W., et al. Overview of distributive energy storage systems for residential communities. in Energytech, 2012 IEEE. 2012. IEEE. 
29. Roberts, B.P. and C. Sandberg, The role of energy storage in development of smart grids. Proceedings of the IEEE, 2011. 99(6): p. 1139-1144.

30. Asgeirsson, H. Status of the community energy storage deployment at DTE energy. in Power and Energy Society General Meeting, 2011 IEEE. 2011. IEEE.

31. International Renewable Energy Agency, I., The transformative Power of Storage: Developing IRENA's Electricity Storage Roadmap. 2014.

32. Akhil, A.A., et al., DOE/EPRI 2013 electricity storage handbook in collaboration with NRECA. 2013: Sandia National Laboratories Albuquerque, NM, USA.

33. Thaller, L.H. Electrically rechargeable redox flow cells. in 9th Intersociety energy conversion engineering conference.

34. De Leon, C.P., et al., Redox flow cells for energy conversion. Journal of Power Sources, 2006. 160(1): p. 716-732.

35. Eyer, J. and G. Corey, Energy storage for the electricity grid: Benefits and market potential assessment guide. Sandia National Laboratories, 2010: p. 69-73.

36. International Energy Agency, I., Technology Roadmap: Solar Photovoltaic Energy - 2014 edition. 2014.

37. Zgraggen, J.-M., Bâtiments résidentiels locatifs à haute performance énergétique: objectifs et réalités. 2010, University of Geneva.

38. Parra, D., G.S. Walker, and M. Gillott, Modeling of PV generation, battery and hydrogen storage to investigate the benefits of energy storage for single dwelling. Sustainable Cities and Society, 2014. 10: p. 1-10.

39. Hoppmann, J., et al., The economic viability of battery storage for residential solar photovoltaic systems-A review and a simulation model. Renewable and Sustainable Energy Reviews, 2014. 39: p. 1101-1118.

40. Parra, D. and M.K. Patel, Effect of tariffs on the performance and economic benefits of PVcoupled battery systems. Applied Energy, 2016. 164: p. 175-187.

41. Wirth, H., Recent Facts about Photovoltaics in Germany. 2015, Fraunhofer ISE.

42. Clover, I., UK to propose drastic FIT cuts starting 2016, in PV Magazine. Photovoltaic market \& Technology. 2015.

43. Peschel, T., Switzerland cuts feed-in tariff for photovoltaics, S.W. ENERGY, Editor. 2014.

44. International Renewable Energy Agency, I., Battery storage for renewables: market status and technology outlook. 2015.

45. Baumann, L. and E. Boggasch, Experimental assessment of hydrogen systems and vanadiumredox-flow-batteries for increasing the self-consumption of photovoltaic energy in buildings. International Journal of Hydrogen Energy, 2015.

46. Parra, D., G.S. Walker, and M. Gillott, Are batteries the optimum PV-coupled energy storage for dwellings? Techno-economic comparison with hot water tanks in the UK. Energy and Buildings, 2016. 116: p. 614-621.

47. Alam, M., K.M. Muttaqi, and D. Sutanto, Mitigation of rooftop solar PV impacts and evening peak support by managing available capacity of distributed energy storage systems. Power Systems, IEEE Transactions on, 2013. 28(4): p. 3874-3884.

48. Ratnam, E.L., S.R. Weller, and C.M. Kellett, An optimization-based approach to scheduling residential battery storage with solar PV: Assessing customer benefit. Renewable Energy, 2015. 75: p. 123-134.

49. Huq, K.M.M., et al. An energy management system for a community energy storage system. in Energy Conversion Congress and Exposition (ECCE), 2012 IEEE. 2012. IEEE.

50. Moshövel, J., et al., Analysis of the maximal possible grid relief from PV-peak-power impacts by using storage systems for increased self-consumption. Applied Energy, 2015. 137: p. 567575.

51. Wolfs, P. and G.S. Reddy. A receding predictive horizon approach to the periodic optimization of community battery energy storage systems. in Universities Power Engineering Conference (AUPEC), 2012 22nd Australasian. 2012. IEEE. 
52. Neubauer, J., et al. Analyzing the Effects of Climate and Thermal Configuration on Community Energy Storage Systems. in Electrical Energy Storage Applications and Technologies (EESAT) Conference. 2013.

53. Beltran, $\mathrm{H}$., et al., Evaluation of storage energy requirements for constant production in PV power plants. Industrial Electronics, IEEE Transactions on, 2013. 60(3): p. 1225-1234.

54. Jabalameli, N., et al. Rooftop PV with battery storage for constant output power production considering load characteristics. in Electrical and Electronics Engineering (ELECO), 2013 8th International Conference on. 2013. IEEE.

55. Parra, D., M. Gillott, and G.S. Walker, The role of hydrogen in achieving the decarbonization targets for the UK domestic sector. International Journal of Hydrogen Energy, 2014. 39(9): p. 4158-4169.

56. Hesaraki, A., S. Holmberg, and F. Haghighat, Seasonal thermal energy storage with heat pumps and low temperatures in building projects-A comparative review. Renewable and Sustainable Energy Reviews, 2015. 43: p. 1199-1213.

57. Alam, M., K.M. Muttaqi, and D. Sutanto, A novel approach for ramp-rate control of solar PV using energy storage to mitigate output fluctuations caused by cloud passing. Energy Conversion, IEEE Transactions on, 2014. 29(2): p. 507-518.

58. Delfanti, M., D. Falabretti, and M. Merlo, Energy storage for PV power plant dispatching. Renewable Energy, 2015. 80: p. 61-72.

59. Bergner, J., et al. Feed-in Power Limitation of Grid-Connected PV Battery Systems with Autonomous Forecast-Based Operation Strategies. in 29th European Photovoltaic Solar Energy Conference and Exhibition. 2014.

60. Zheng, M., C.J. Meinrenken, and K.S. Lackner, Agent-based model for electricity consumption and storage to evaluate economic viability of tariff arbitrage for residential sector demand response. Applied Energy, 2014. 126: p. 297-306.

61. Erdinc, O., et al., A new perspective for sizing of distributed generation and energy storage for smart households under demand response. Applied Energy, 2015. 143: p. 26-37.

62. Parra, D., et al., Optimum community energy storage system for demand load shifting. Applied Energy, 2016. 174: p. 130-143.

63. Parra, D., M. Gillott, and G.S. Walker, Design, testing and evaluation of a community hydrogen storage system for end user applications. International Journal of Hydrogen Energy, 2016.

64. Fazeli, A., et al. A novel stochastic modelling approach for electric vehicle charging power and energy requirements. in Innovative Smart Grid Technologies Conference (ISGT), 2015 IEEE Power \& Energy Society. 2015. IEEE.

65. Leadbetter, J. and L. Swan, Battery storage system for residential electricity peak demand shaving. Energy and Buildings, 2012. 55: p. 685-692.

66. Jargstorf, J., C. De Jonghe, and R. Belmans, Assessing the reflectivity of residential grid tariffs for a user reaction through photovoltaics and battery storage. Sustainable Energy, Grids and Networks, 2015. 1: p. 85-98.

67. Barzin, R., et al., Peak load shifting with energy storage and price-based control system. Energy, 2015.

68. Ruddell, B.L., F. Salamanca, and A. Mahalov, Reducing a semiarid city's peak electrical demand using distributed cold thermal energy storage. Applied Energy, 2014. 134: p. 35-44.

69. Sun, Y., et al., Peak load shifting control using different cold thermal energy storage facilities in commercial buildings: A review. Energy Conversion and Management, 2013. 71: p. 101114.

70. Dott, R., The Reference Framework for System Simulations of the IEA SHC Task 44 / HPP Annex 38, Part B: Buildings and Space Heat Load. 2013, IEA.

71. Gohl, N., et al., Highly efficient, cost-effective solar-geothermal heat supply concept for multifamily houses and small residential areas, in CISBAT 2015 - September 9-11, 2015 - Lausanne, Switzerland. 2015. 
72. Navarro, L., et al., Thermal energy storage in building integrated thermal systems: A review. Part 2. Integration as passive system. Renewable Energy, 2015. 85: p. 1334-1356.

73. Kenisarin, M. and K. Mahkamov, Passive thermal control in residential buildings using phase change materials. Renewable and Sustainable Energy Reviews, 2016: p. 371-398.

74. CIGALE, S.C.D.H.L. La Cigale. 2013.

75. Mastani Joybari, M., et al., Heat and cold storage using phase change materials in domestic refrigeration systems: The state-of-the-art review. Energy and Buildings, 2015. 106: p. 111124.

76. Barbieri, E.S., F. Melino, and M. Morini, Influence of the thermal energy storage on the profitability of micro-CHP systems for residential building applications. Applied Energy, 2012. 97: p. 714-722.

77. Kreuder, L. and C. Spataru, Assessing demand response with heat pumps for efficient grid operation in smart grids. Sustainable Cities and Society, 2015. 19: p. 136-143.

78. A. Arteconi, N.J.H., F. Polonara, State of the art of thermal storage for demand-side management. Applied Energy, 2012. 93: p. 371-389.

79. Hinds, E. and J. Boyer-Dry, The emergence of an electric energy storage market. The Electricity Journal, 2014. 27(2): p. 6-13.

80. Aecom, Energy Storage Study: Funding and Knowledge Sharing Priorities. 2015, Australian Renewable Energy Agency.

81. Energy, U.S.D.o., Grid Energy Storage. 2013.

82. Energy Research, P., The future role of energy storage in the UK. 2011.

83. Clean Energy, G., Energy Storage and Electricity Markets: the value of storage to the power system and the importance of electricity in energy storage economics. 2015.

84. Castillo, A. and D.F. Gayme, Grid-scale energy storage applications in renewable energy integration: A survey. Energy Conversion and Management, 2014. 87: p. 885-894.

85. Di Giorgio, A. and F. Liberati, Near real time load shifting control for residential electricity prosumers under designed and market indexed pricing models. Applied Energy, 2014. 128: p. 119-132.

86. Pourmousavi, S.A., S.N. Patrick, and M.H. Nehrir, Real-time demand response through aggregate electric water heaters for load shifting and balancing wind generation. Smart Grid, IEEE Transactions on, 2014. 5(2): p. 769-778.

87. Świerczyński, M., et al., Field Experience from Li-Ion BESS Delivering Primary Frequency Regulation in the Danish Energy Market. ECS Transactions, 2014. 61(37): p. 1-14.

88. Tielens, P. and D. Van Hertem, Grid inertia and frequency control in power systems with high penetration of renewables. status: published, 2012.

89. Fuel, C. and U. Hydrogen Joint, Commercialisation of Energy Storage in Europe. 2015, European Union.

90. Amor, M.B., et al., Influence of wind power on hourly electricity prices and GHG (greenhouse gas) emissions: Evidence that congestion matters from Ontario zonal data. Energy, 2014. 66 p. 458-469.

91. Kousksou, T., et al., Energy storage: Applications and challenges. Solar Energy Materials and Solar Cells, 2014. 120: p. 59-80.

92. Kjaer, P.C., R. Larke, and G.C. Tarnowski. Ancillary services provided from wind power plant augmented with energy storage. in Power Electronics and Applications (EPE), 2013 15th European Conference on. IEEE.

93. International Energy, A. Technology Roadmap-Energy Storage. IEA Paris, France.

94. Rastler, D., Electricity energy storage technology options: a white paper primer on applications, costs and benefits. 2010: Electric Power Research Institute.

95. Black, V., Cost and Performance Data for Power Generation Technologies. Prepared for the National Renewable Energy Laboratory, 2012.

96. International Energy Agency, I., Energy Technology Perspectives 2014. Harnessing Electricity's potential. 2014, International Energy Agency, IEA. 
97. International Energy, A., Technology Roadma. Energy Storage. 2014, IEA Paris, France.

98. Soloveichik, G.L., Battery technologies for large-scale stationary energy storage. Annua review of chemical and biomolecular engineering, 2011. 2: p. 503-527.

99. Eckroad, S. and I. Gyuk, EPRI-DOE handbook of energy storage for transmission \& distribution applications. Electric Power Research Institute, Inc, 2003.

100. Vazquez, S., et al., Energy storage systems for transport and grid applications. Industrial Electronics, IEEE Transactions on, 2010. 57(12): p. 3881-3895.

101. McKeon, B.B., J.-i. Furukawa, and S. Fenstermacher, Advanced lead-acid batteries and the development of grid-scale energy storage systems. Proceedings of the IEEE, 2014. 102(6): p. 951-963.

102. Terada, M. and H. Takabayashi, Industrial Storage Device for Low-carbon Society. Hitachi Review, 2011. 60(1): p. 23.

103. Yoshida, H., et al. Development of an ultra long-life (6000 cycles) VRLA for deep-cycle service. in Proc. 13th Asian Battery Conf., Macau, China. 2009.

104. Scrosati, B. and J. Garche, Lithium batteries: Status, prospects and future. Journal of Power Sources, 2010. 195(9): p. 2419-2430.

105. $\mathrm{Xu}, \mathrm{T}$., et al., Lithium-ion batteries for stationary energy storage. JOM, 2010. 62(9): p. 24-30 106. Goodenough, J.B. and K.-S. Park, The Li-ion rechargeable battery: a perspective. Journal of the American Chemical Society, 2013. 135(4): p. 1167-1176.

107. Stroe, A.-I., et al. Performance model for high-power lithium titanate oxide batteries based on extended characterization tests. in Energy Conversion Congress and Exposition (ECCE), 2015 IEEE. IEEE.

108. Stroe, D.-I., et al., Accelerated lifetime testing methodology for lifetime estimation of Lithiumion batteries used in augmented wind power plants. Industry Applications, IEEE Transactions on, 2014. 50(6): p. 4006-4017.

109. Omar, N., et al. Assessment of performance of lithium iron phosphate oxide, nickel manganese cobalt oxide and nickel cobalt aluminum oxide based cells for using in plug-in battery electric vehicle applications. in Vehicle Power and Propulsion Conference (VPPC), 2011 IEEE. IEEE.

110. Poullikkas, A., A comparative overview of large-scale battery systems for electricity storage. Renewable and Sustainable Energy Reviews, 2013. 27: p. 778-788.

111. Jaffe, S. The Lithium Ion Battery Market Supply and Demand. in Navigant Consulting Inc. Presented at the ARPA-E Range Conference on January. 2014.

112. Grothoff, J.M., BATTERY STORAGE FOR RENEWABLES: MARKET STATUS AND TECHNOLOGY OUTLOOK. 2015.

113. International Renewable Energy Agency, I., Road Transport: The cost of Renewable Solutions. 2013.

114. Kawakami, N., et al. Development and field experiences of stabilization system using $34 \mathrm{MW}$ NAS batteries for a 51MW wind farm. in Industrial Electronics (ISIE), 2010 IEEE International Symposium on. IEEE.

115. Fabjan, C., et al., The vanadium redox-battery: an efficient storage unit for photovoltaic systems. Electrochimica Acta, 2001. 47(5): p. 825-831.

116. Horne, C., et al., Demonstration of EnerVault Iron-Chromium Redox Flow Battery. 2014, California Energy Commission.

117. Weber, A.Z., et al., Redox flow batteries: a review. Journal of Applied Electrochemistry, 2011. 41(10): p. 1137-1164.

118. Skyllas-Kazacos, M. and F. Grossmith, Efficient vanadium redox flow cell. Journal of the Electrochemical Society, 1987. 134(12): p. 2950-2953.

119. Zeng, Y.K., et al., A comparative study of all-vanadium and iron-chromium redox flow batteries for large-scale energy storage. Journal of Power Sources, 2015. 300: p. 438-443.

120. Miller, A.R., K.S. Hess, and D.L. Barnes. Comparison of Practical Hydrogen-Storage Volumetric Densities. in Proceedings of the NHA Annual Hydrogen Conference. 2007. 
121. Parra, D. and M.K. Patel, Techno-economic implications of the electrolyser technology and size for power-to-gas systems. International Journal of Hydrogen Energy, 2016. 41(6): p. 3748-3761.

122. Bhandari, R., C.A. Trudewind, and P. Zapp, Life cycle assessment of hydrogen production via electrolysis - a review. Journal of Cleaner Production, 2014. 85: p. 151-163.

123. Bessarabov, D., et al., PEM Electrolysis for Hydrogen Production: Principles and Applications. 2016: CRC Press.

124. Hofstetter, D., et al., Power-to-Gas in Switzerland - Demand, Regulation, Economics, Technical Potential. 2014.

125. Cai, Q., C.S. Adjiman, and N.P. Brandon, Optimal control strategies for hydrogen production when coupling solid oxide electrolysers with intermittent renewable energies. Journal of Power Sources, 2014. 268: p. 212-224.

126. Walker, G., Solid-state hydrogen storage: materials and chemistry. 2008: Elsevier.

127. Staffell, I. and R. Green, The cost of domestic fuel cell micro-CHP systems. International Journal of hydrogen energy, 2013. 38(2): p. 1088-1102.

128. Berger, R., Advancing Europe's energy system: stationary fuel cells in distributed generation / Publications/ Media/ Roland Berger. 2015.

129. Steward, D., Community Energy: Analysis of Hydrogen Distributed Energy Systems with Photovoltaics for Load Leveling and Vehicle Refueling. 2014, National Renewable Energy Laboratory.

130. Luo, X., et al., Overview of current development in electrical energy storage technologies and the application potential in power system operation. Applied Energy, 2015. 137: p. 511-536.

131. Makarov, Y.V., et al., Sizing Energy Storage to Accommodate High Penetration of Variable Energy Resources. IEEE Transactions on Sustainable Energy, 2012. 3(1): p. 34-40.

132. Tan, X., Q. Li, and H. Wang, Advances and trends of energy storage technology in Microgrid. Electrical Power and Energy Systems, 2013. 44: p. 179-191.

133. Bocklisch, T., Hybrid energy storage systems for renewable energy applications. Energy Procedia, 2015. 73: p. 103-111.

134. Mangold Dirk, M.O., Tziggili Ekaterini Primoudi, Thomas Schmidt, Markus Unterberger, Beatrice Zeh, Technisch-Wirtschaftliche Analyse Und Weiterentwicklung Der Solaren Langzeit-Wärmespeicherung. 2012, Solites.

135. Moreno, P., et al., The use of phase change materials in domestic heat pump and airconditioning systems for short term storage: A review. Renewable and Sustainable Energy Reviews, 2014. 39: p. 1-13.

136. Seddegh, S., et al., Solar domestic hot water systems using latent heat energy storage medium: A review. Renewable and Sustainable Energy Reviews, 2015. 49: p. 517-533.

137. Winteler, C., et al., Seasonal Performance of a Combined Solar, Heat Pump and Latent Heat Storage System. Energy Procedia, 2014. 48: p. 689-700.

138. Sommer, W., et al., Optimization and spatial pattern of large-scale aquifer thermal energy storage. Applied Energy, 2015. 137: p. 322-337.

139. Schmidt, T., Solar district heating guidelines - Fact sheet 7.2. 2012. p. 13

140. Holm, L., Long term experiences with solar district heating in Denmark. 2012, EUROHEAT: Brussels.

141. Mathieu Riegger, D.M. Seasonal thermal energy storage (STES). in 3rd Swiss Symposium Thermal Energy Storage. 2016. Lucerne (Switzerland).

142. Jülch, V., et al., A holistic comparative analysis of different storage systems using levelized cost of storage and life cycle indicators. Energy Procedia, 2015. 73: p. 10.

143. Cui, B., et al., Effectiveness and life-cycle cost-benefit analysis of active cold storages for building demand management for smart grid applications. Applied Energy, 2015. 147: p. 523535 . 
144. Gwerder, D., et al., Entwicklung einer optimalen Einheit aus Wärmepumpe und thermischem Energiespeicher, in 21. Wärmepumpentagung. 2015, Swiss Federal Office of Energy: Burgdorf, Switzerland. p. 1-12.

145. Blarke, M.B., et al., Thermal battery with $\mathrm{CO} 2$ compression heat pump: Techno-economic optimization of a high-efficiency Smart Grid option for buildings. Energy and Buildings, 2012. 50: p. 128-138.

146. AG, J.E. 2016 [cited 2016 09.05.2016]; Available from: http://jenni.ch/preise-2.html.

147. OVO Energy, Community Energy White Paper April 2014. 2014.

148. Caird, S. and R. Roy, Adoption and Use of Household Microgeneration Heat Technologies. Low Carbon Economy, 2010. 1(2): p. 61-70.

149. Michelsen, C.C. and R. Madlener, Motivational factors influencing the homeowners' decisions between residential heating systems: An empirical analysis for Germany. Energy Policy, 2013. 57: p. 221-233.

150. Claudy, M., R. Garcia, and A. O'Driscoll, Consumer resistance to innovation-a behavioral reasoning perspective. Journal of the Academy of Marketing Science, 2015. 43(4): p. 528-544.

151. Mahesh, A. and K.S. Sandhu, Hybrid wind/photovoltaic energy system developments: Critical review and findings. Renewable and Sustainable Energy Reviews, 2015. 52: p. 1135-1147.

152. Seyfang, G., et al., A grassroots sustainable energy niche? Reflections on community energy in the UK. Environmental Innovation and Societal Transitions, 2014. 13: p. 21-44.

153. Comittee, H.o.C.E.a.C.C., Local Energy: Volume II Addtional written evidence. 2013, The Stationery Office Limited. p. 14.

154. Hannon, M.J. and R. Bolton, UK Local Authority engagement with the Energy Service Company (ESCO) model: Key characteristics, benefits, limitations and considerations. Energy Policy, 2015. 78: p. 198-212.

155. Mayer, J. STATE INCENTIVE PROGRAM IS LAUNCHED FOR SOLAR STORAGE SYSTEMS. 2013; Available from: http://www.solarenergystorage.org/en/staatliche-forderung-vonsolarstromspeichern-gestartet/.

156. Bomberg, E. and N. McEwen, Mobilizing community energy. Energy Policy, 2012. 51: p. 435444.

157. Shamsuzzoha, A., A. Grant, and J. Clarke, Implementation of renewable energy in Scottish rural area: A social study. Renewable and Sustainable Energy Reviews, 2012. 16(1): p. 185191.

158. Heiskanen, E., et al., Low-carbon communities as a context for individual behavioural change. Energy Policy, 2010. 38(12): p. 7586-7595.

159. Rodrigues, L., Marsh, J., Kiamba, L., Gillott, M., O'Doherty, T., The Case for Localised Energy Management to Support Resilient Cities, in Passive and Low-Energy Architecture - PLEA 2016: Cities, Buildings, People: Towards Regenerative Environments. . 2016: Los Angeles.

160. DECC, Low Carbon Communities Challenge Evaluation Report 2012, Department of Energy and Climate Change: London, UK.

161. ISO, 14040 Environmental management - Life cycle assessment - Principles and framework 2006: Switzerland.

162. Sullivan, J.L. and L. Gaines, Status of life cycle inventories for batteries. Energy Conversion and Management, 2012. 58: p. 134-148.

163. Oliveira, L., et al., Environmental performance of electricity storage systems for grid applications, a life cycle approach. Energy Conversion and Management, 2015. 101(0): p. 326-335.

164. Sternberg, A. and A. Bardow, Power-to-What? - Environmental assessment of energy storage systems. Energy \& Environmental Science, 2015. 8(2): p. 389-400.

165. Denholm, P. and G. Kulcinski, Net energy balance and greenhouse gas emissions from renewable energy storage systems 2003, Energy Center of Wisconsin, Fusion Technology Institute University of Wisconsin-Madison. 
166. Jülch, V., et al., A Holistic Comparative Analysis of Different Storage Systems using Levelized Cost of Storage and Life Cycle Indicators. Energy Procedia, 2015. 73: p. 18-28.

167. Hawkins, T.R., O.M. Gausen, and A.H. Strømman, Environmental impacts of hybrid and electric vehicles-a review. The International Journal of Life Cycle Assessment, 2012. 17(8): p. 997-1014.

168. Nordelöf, A., et al., Environmental impacts of hybrid, plug-in hybrid, and battery electric vehicles-what can we learn from life cycle assessment? The International Journal of Life Cycle Assessment, 2014: p. 1-25.

169. Majeau-Bettez, G., T.R. Hawkins, and A.H. Strømman, Life Cycle Environmental Assessment of Lithium-Ion and Nickel Metal Hydride Batteries for Plug-In Hybrid and Battery Electric Vehicles. Environmental Science \& Technology, 2011. 45(10): p. 4548-4554.

170. Zackrisson, M., L. Avellán, and J. Orlenius, Life cycle assessment of lithium-ion batteries for plug-in hybrid electric vehicles - Critical issues. Journal of Cleaner Production, 2010. 18(15): p. 1519-1529.

171. Notter, D.A., et al., Contribution of Li-Ion Batteries to the Environmental Impact of Electric Vehicles. Environmental Science \& Technology, 2010. 44(17): p. 6550-6556.

172. Messagie, M., et al., 11 - Environmental performance of lithium batteries: life cycle analysis, in Rechargeable Lithium Batteries, A.A. Franco, Editor. 2015, Woodhead Publishing. p. 303318.

173. Longo, S., et al., Life cycle assessment of storage systems: the case study of a sodium/nickel chloride battery. Journal of Cleaner Production, 2014. 85: p. 337-346.

174. Denholm, P. and G.L. Kulcinski, Life cycle energy requirements and greenhouse gas emissions from large scale energy storage systems. Energy Conversion and Management, 2004. 45(1314): p. 2153-2172.

175. Raluy, R.G., et al., Life Cycle Assessment of Central Solar Heating Plants with Seasonal Storage. Energy Procedia, 2014. 48: p. 966-976.

176. Comodi, G., et al., Life cycle assessment and energy-CO2-economic payback analyses of renewable domestic hot water systems with unglazed and glazed solar thermal panels. Applied Energy, 2016. 164: p. 944-955.

177. Simons, A. and S.K. Firth, Life-cycle assessment of a $100 \%$ solar fraction thermal supply to a European apartment building using water-based sensible heat storage. Energy and Buildings, 2011. 43(6): p. 1231-1240.

178. Oró, E., et al., Comparative life cycle assessment of thermal energy storage systems for solar power plants. Renewable Energy, 2012. 44: p. 166-173.

179. Kuznar, Z., Duke Energy. NAATBatt Annual Meeting. 2013: Austin, Texas.

180. Reliability., D.D.o.E.O.o.E.D.E., DOE GLOBAL ENERGY STORAGE DATABASE. 2015.

181. Thomas, P., T. Walker, and C. McCarthy. Demonstration of Community Energy Storage fleet for load leveling, reactive power compensation, and reliability improvement. in Power and Energy Society General Meeting, 2012 IEEE. 2012. IEEE.

182. Australian Renewable Energy Agency, A., Solar and storage trial at Alkimos Beach residential development. 2015

183. eCAMION, eCAMION delivers Community Energy Storage to Toronto Hydro. 2015.

184. Alam, M.J.E., K.M. Muttaqi, and D. Sutanto, Community energy storage for neutral voltage rise mitigation in four-wire multigrounded LV feeders with unbalanced solar PV allocation. Smart Grid, IEEE Transactions on, 2015. 6(6): p. 2845-2855.

185. Hinz, H., B. Zuber, and J. Kilz. Development of a hybrid power generation system. in PCIM Europe 2014; International Exhibition and Conference for Power Electronics, Intelligent Motion, Renewable Energy and Energy Management; Proceedings of. 2014. VDE.

186. Karvonen, A., et al. Pathways to Zero Carbon Housing in the UK. in Workshop presentation presented at the Zero Carbon Habitation workshop, February. 2013.

187. COMPANY, S.C.E. S\&C Energy Storage System to Provide Grid Support for PJM. 2014. 
188. Timmerman, M. In an Australian first, Ergon Energy expects to be installing new batterybased technology called Grid Utility Support Systems (GUSS) to help power sections of its electricity network by mid-2015. 2015.

189. Corporation, D.E. Energy Storage. 2015.

190. Doering, R. World's First Renewables Hydrogen Hybrid Power Plant Starts Production. 2011 [cited 2016 Jan 16]; Available from: http://www.hfcletter.com/Content/Renewplant.aspx.

191. VETTERLI, N. and M. SULZER. Dynamic analysis of the low-temperature district network"'" Suurstoffi"" through monitoring. in Proceedings of International Conference CISBAT 2015 Future Buildings and Districts Sustainability from Nano to Urban Scale. 2015. LESO-PB, EPFL.

192. Hobson, K., J. Hamilton, and R. Mayne, Monitoring and evaluation in UK low-carbon community groups: benefits, barriers and the politics of the local. Local Environment, 2014(ahead-of-print): p. 1-13.

193. Comission, E. Empowering customers to save energy by informative billing (EMPOWERING). 2015; Available from:

https://ec.europa.eu/energy/intelligent/projects/en/projects/empowering.

194. Fitzgerald, G., Aggregated Energy Storage Has Arrived. 2015.

195. UK Power Networkds, B. Smarter Network Storage - business model consultation. 2013; Available from: http://innovation.ukpowernetworks.co.uk/innovation/en/Projects/tier-2projects/Smarter-Network-Storage-(SNS)/Project-Documents/Smarter-Network-StorageBusiness-model-consultation.pdf.

196. Dudek, K. and R. Lane. Synergy between Electrified Vehicle and Community Energy Storage Batteries and Markets. in Power and Energy Society General Meeting. 2011. San Diego, CA.

197. Wüstenhagen, R., M. Wolsink, and M.J. Bürer, Social acceptance of renewable energy innovation: An introduction to the concept. Energy Policy, 2007. 35(5): p. 2683-2691.

198. Stephen Hall and Katy Roelich Local Electricity Supply: Opportunities, archetypes and outcomes. Ibuild/Realising Transition Pathways Independent Report, 2015.

199. Couture, T. and Y. Gagnon, An analysis of feed-in tariff remuneration models: Implications for renewable energy investment. Energy Policy, 2010. 38(2): p. 955-965.

200. Lipp, J., Lessons for effective renewable electricity policy from Denmark, Germany and the United Kingdom. Energy Policy, 2007. 35(11): p. 5481-5495.

201. DECC, Consultation on a review of the Feed-in Tariffs scheme. 2015, Department of Energy and Climate Change: London, UK.

202. Warren, C.R. and R.V. Birnie, Re-powering Scotland: Wind Farms and the 'Energy or Environment?' Debate. Scottish Geographical Journal, 2009. 125(2): p. 97-126.

203. Verbrauchrschutz, B.d.J.u.f., Verordnung über die Entgelte für den Zugang zu Elektrizitätsversorgungsnetzen (Stromnetzentgeltverordnung - StromNEV) \& 18 Entgelt für dezentrale Einspeisung, B.d.J.u.f. Verbrauchrschutz, Editor.

204. Markus, A., Stromspeicher auf Quartiersebene-Analyse und Entwicklung eines Geschäftsmodells zur lokalen Stromnutzung und Vermarktung im Quartier. 2015, AlbertLudwigs-Universität Freiburg.

205. V., B.d.E.-u.W.e., Strompreisanalyse März 2015. 2015.

206. Hargreaves, T., et al., Grassroots innovations in community energy: The role of intermediaries in niche development. Global Environmental Change, 2013. 23(5): p. 868-880.

207. England, C.E., Community Energy England. 2014.

208. Sorrell, S., The economics of energy service contracts. Energy Policy, 2007. 35(1): p. 507-521 209. Bertoldi, P., Boza-Kiss, B., Panev, S., Labanca, N., ESCo Market Report 2013. 2014, European Commission Joint Research Centre, Institute for Energy and Transport Luxembourg. 